\title{
Population Dynamics Of Mottled Sculpin (Pisces) In A Variable Environment: Information Theoretic Approaches
}

Gary D. Grossman

Robert E. Ratajczak Jr.

J. Todd Petty

Mark D. Hunter

James T.Peterson

See next page for additional authors

Follow this and additional works at: https://researchrepository.wvu.edu/faculty_publications

\section{Digital Commons Citation}

Grossman, Gary D.; Ratajczak Jr., Robert E.; Petty, J. Todd; Hunter, Mark D.; Peterson, James T.; and Grenouillet, Gael, "Population Dynamics Of Mottled Sculpin (Pisces) In A Variable Environment: Information Theoretic Approaches" (2006). Faculty Scholarship. 637.

https://researchrepository.wvu.edu/faculty_publications/637 
Authors

Gary D. Grossman, Robert E. Ratajczak Jr., J. Todd Petty, Mark D. Hunter, James T. Peterson, and Gael Grenouillet 


\title{
POPULATION DYNAMICS OF MOTTLED SCULPIN (PISCES) IN A VARIABLE ENVIRONMENT: INFORMATION THEORETIC APPROACHES
}

\author{
Gary D. Grossman, ${ }^{1,6}$ Robert E. Ratajczak, Jr., ${ }^{1}$ J. Todd Petty, ${ }^{1,2}$ Mark D. Hunter ${ }^{3}$ \\ James T. Peterson, ${ }^{4}$ and Gael Grenouillet ${ }^{5}$ \\ ${ }^{1}$ D. B. Warnell School of Forest Resources, University of Georgia, Athens, Georgia 30602 USA \\ ${ }^{2}$ Division of Forestry, West Virginia University, Morgantown, West Virginia 26506 USA \\ ${ }^{3}$ Institute of Ecology, University of Georgia, Athens, Georgia 30602 USA \\ ${ }^{4}$ U.S. Geological Survey, Georgia Cooperative Fish and Wildlife Research Unit, Warnell School of Forest Resources, \\ University of Georgia, Athens, Georgia 30602 USA \\ ${ }^{5}$ Laboratoire de Dynamique Biodiversite, UMR 5172, CNRS-Universite Paul Sabatier 31062 Toulouse Cedex 4 France
}

\begin{abstract}
We used strong inference with Akaike's Information Criterion (AIC) to assess the processes capable of explaining long-term (1984-1995) variation in the per capita rate of change of mottled sculpin (Cottus bairdi) populations in the Coweeta Creek drainage (USA). We sampled two fourth- and one fifth-order sites (BCA [uppermost], BCB, and CC [lowermost]) along a downstream gradient, and the study encompassed extensive flow variation. Physical habitat availability varied significantly both within and among the sites.

Sculpin densities in all sites were highly stable (coefficients of variation $=0.23-0.41$ ) and sampling variability was low (coefficients of variation $=0.11-0.15$ ). Population stability was positively associated with habitat stability, and the only significant correlations of population parameters among sites involved juveniles. Sculpin densities were significantly higher in BCB than in CC. The data suggest that, despite their proximity, the dynamics of populations within the sites are being determined by small-scale (i.e., $30-50 \mathrm{~m}$ ) rather than broad-scale spatial processes.

Both AIC and Dennis and Taper analyses indicated that simple density dependence had the greatest ability to explain variation in $r$ for all life-history classes in all sites (AIC, seven of nine cases; Dennis and Taper, nine of nine cases). Multiprocess models had little explanatory power. When adults were removed from two sites, juvenile sculpin shifted into microhabitats formerly occupied by adults. No shifts occurred in control sites. Consequently, it is likely that the patterns of density dependence observed in all three sites were a consequence of intraspecific competition for space. Our findings argue for a multitiered approach to the study of population variation, one that encompasses long-term monitoring, spatial variation, and experimental testing of potential mechanisms.

Key words: Cottus bairdi; density dependence; density independence; floods and droughts; longterm population studies; mottled sculpin; population regulation; recruitment limitation; removal experiments; stream fish.
\end{abstract}

\section{INTRODUCTION}

Quantifying the dynamics of natural populations has interested ecologists for centuries (McIntosh 1985); nonetheless, there remain few studies that document the processes responsible for fluctuating abundances in natural populations (Murdoch 1994). This dearth is due to many factors including: (1) the logistical difficulties of obtaining adequate time series of population data for meaningful statistical analyses, especially for vertebrates (Hixon et al. 2002), (2) statistical uncertainties inherent in the correlational analyses typically used to detect associations between population time series and potential causal factors (e.g., density, disturbance) (Dennis and Taper 1994, Shenk et al. 1998, Dennis and

Manuscript received 26 October 2004; revised 19 May 2005; accepted 23 June 2005; final version received 6 September 2005 Corresponding Editor: A. S. Flecker.

${ }^{6}$ E-mail: grossman@uga.edu
Otten 2000), (3) the inability of traditional frequentist statistics to evaluate simultaneously the relative importance of potential causal factors (Burnham and Anderson 2002), and (4) difficulties in conducting population-level experiments to evaluate the relative effects of the potential causal processes identified in descriptive studies.

In general, the processes capable of determining population abundance can be classified as either density dependent or density independent. Density-dependent forces act through negative feedback (typically intraspecific competition or predation) between abundance and demographic traits such as growth, reproductive success, dispersal, or survivorship. Density-dependent processes appear to be the only forces capable of generating populations with stable abundances (i.e., those with relatively stationary long-term mean abundances and stable and low variance [Grossman et al. 1990, Murdoch 1994]), although such populations are not the 

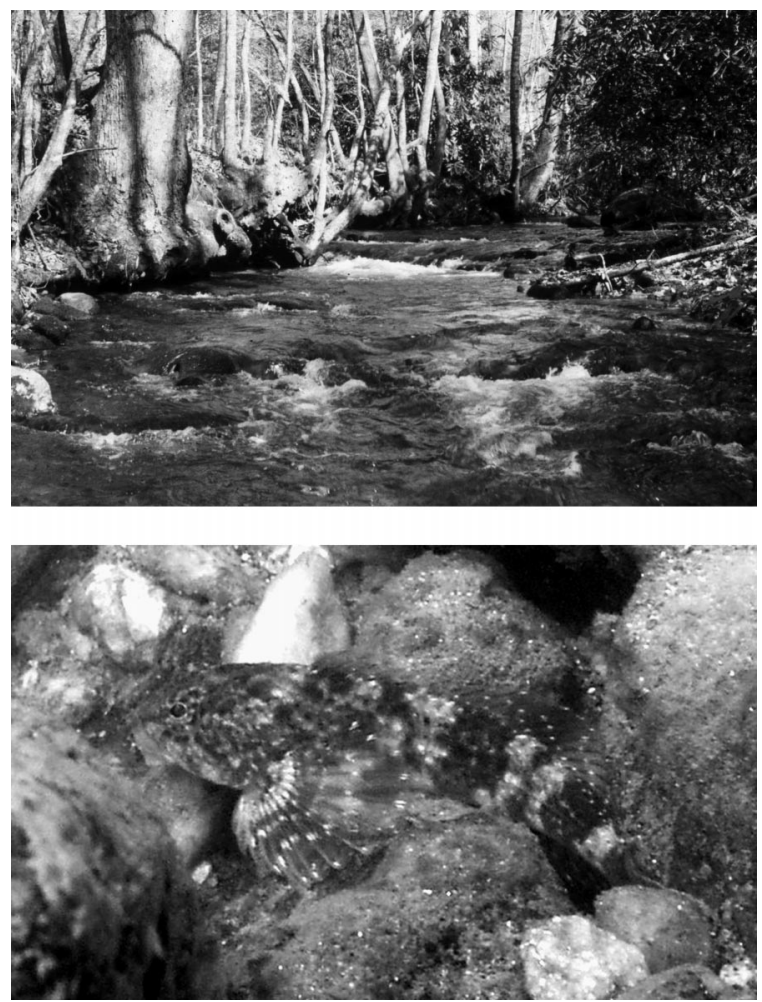

Plate 1. (Upper) One of the sites in Shope Fork where the Cottus removal experiment was conducted, and (lower) an underwater shot of an adult Cottus bairdi. Photo credits: J. Todd Petty (upper) and Duncan Elkins (lower).

only ones that density dependence can act on (Cappuccino and Price 1995, Turchin and Hanski 2001).

By contrast, density-independent processes typically affect populations either via mortality produced by environmental disturbances (e.g., hurricanes, floods, droughts), or through high survivorship facilitated by unusually favorable environmental conditions (e.g., year-class phenomena [Danilowicz 1997]). Consequently, long-term abundance values for these populations can best be described as a statistical random walk, with the variance increasing with time (Murdoch 1994). Recruitment limitation is a special case of density independence in which population size is determined by the abundance of new year classes entering the population (i.e., population size at time $t+1$ is a positive function of the number of recruits at time $t$ [Danilowicz 1997]). Recruitment limitation typically is produced by variation in favorable and unfavorable environmental conditions. The abundances of species affected by this process fluctuate in a manner similar to those of completely density-independent populations, except for the presence of serial correlations in annual abundance produced by strong year classes (Danilowicz 1997). A further implication of recruitment limitation and density independence in general is that population size is not limited by local resource availability.
Studies conducted over the last decade have shown that multiple processes (e.g., density dependence, density independence, recruitment limitation) influence the abundance of populations, and these processes vary in both complexity and context (i.e., spatial and temporal characteristics of a population [Pulliam and Danielson 1991, Turchin and Hanski 2001, Hixon et al. 2002]). For example, density dependence alone can be manifested as a simple process $\left(N_{t}\right.$ is a function of $\left.N_{t-1}\right)$, a complex process $\left(N_{t}\right.$ is a function of $N_{t-1}$ of multiple life-history classes), or a delayed response (e.g., $N_{t}$ is a function of $N_{t-2}$ [Hunter 1998, Turchin and Hanski 2001, Hixon et al. 2002]).

Stream-dwelling organisms are good subjects for investigations of population regulation because they commonly are subjected to substantial environmental variation in the form of both seasonal and annual changes in mean flows as well as extreme events such as floods and droughts (Grossman et al. 1982, 1998, Poff and Allen 1995, Lake 2000). Hence, stream organisms may frequently experience density-independent sources of mortality, in addition to the densitydependent factors already operating within these populations. Streams also tend to exhibit high spatial and temporal patchiness in their physical and biological characteristics (Grossman et al. 1995a, Lake 2000, Thompson et al. 2001), which may contribute to smallscale population differentiation.

In this study we employ a strong inference approach (Platt 1964) using Aikaike's Information Criterion (AIC [Burnham and Anderson 2002]), to evaluate a series of ecologically realistic, a priori models potentially capable of explaining long-term variation in per capita rate of increase data for mottled sculpin (Cottus bairdi). We monitored long-term trends in abundance (1984-1995, 3-4 mottled sculpin generations) in three sites along a longitudinal gradient in the Coweeta Creek drainage, to determine if these trends were consistent with the patterns produced by both separate and combined models of density dependence, density independence, and recruitment limitation. Finally, we directly evaluated the short-term effects of intraspecific competition for space between adults and juveniles (i.e., a density-dependent process) by conducting a field removal experiment.

\section{Methods}

\section{Mottled sculpin as a test system}

We chose the mottled sculpin (Cottus bairdi; see Plate 1) (henceforth sculpin) as a study organism because it is the most abundant fish in the Coweeta Creek drainage (Freeman et al. 1988; G. D. Grossman, unpublished data), as it is in many other North America streams (Grossman et al. 1995b, 2002). This species exhibits readily separable life-history classes, which facilitates identification of interactions among these classes (Appendix). Sculpin are small (maximum stan- 
dard length $<150 \mathrm{~mm}$ ) benthic invertivores (Stouder 1990) that reach a maximum age of $7+$ years in the Coweeta drainage and have low fecundity (maximum $=166$ eggs [Grossman et al. 2002]). The species displays highly restricted movements, and adults and juveniles exhibit mean signed movement rates ranging from 0.04 to $1.57 \mathrm{~m}$ over a $45-\mathrm{d}$ period (data for three 45-d periods per year, 1994-1995 [Petty and Grossman 2004]). In addition, Petty and Grossman (2004) showed that most sculpin captured in spring remained within the 200-m study site until the end of autumn in a given year (mean annual rate $=65 \%$ ). As sculpin grow, they shift from shallower microhabitats dominated by depositional substrata (bedrock, sand, and gravel) to deeper areas dominated by erosional (cobble, boulder) substrata (Grossman and Ratajczak 1998). Although physical factors play a role in microhabitat selection, the best predictor of patch use by sculpin is prey abundance within a microhabitat (Petty and Grossman 1996, Petty 1998).

There is strong inferential evidence that the relative stability of sculpin populations in the Coweeta Creek drainage is maintained via density-dependent interactions, specifically intraspecific competitive interactions for food or foraging sites. First, there is little evidence that either interspecific competition or predation significantly affect use of spatial and trophic resources or abundance of sculpin in our study sites (Barrett 1989, Stouder 1990, Grossman et al. 1995b, 1998). Second, mark-recapture studies suggest that immigration and emigration processes play little role in the dynamics of these populations (Petty and Grossman 2004). Third, adults numerically dominate sculpin populations at Coweeta and also occupy more exclusive and more profitable (i.e., higher prey abundance and prey immigration rates) territories than juveniles (Petty 1998, Petty and Grossman 2004). These characteristics translate into differences in fitness, because adults display both higher growth and survivorship rates than juveniles (Petty 1998, Petty and Grossman 2004). Fourth, when adults abandon a territory, the new territory has significantly higher prey densities than those present in the abandoned territory, but this is not true for juveniles (Petty 1998). Fifth, although movement rates are low overall, both adults and juveniles display higher movement rates when adults are more abundant (Petty and Grossman 2004). Sixth, the relative distribution of adults and juveniles across reaches in the Coweeta drainage provides a good fit to the ideal-despotic model of habitat selection (Fretwell 1972), a model based on strong intraspecific competition (Petty 1998). Finally, previous studies demonstrate that sculpin populations in the Coweeta drainage have very stable abundances (i.e., coefficients of variation for mean abundances $<0.34$ ) (Freeman et al. 1988, Grossman et al. 1990) despite significant environmental variability, which suggests that density dependence may be present.

\section{Population study sites}

We chose three $30 \mathrm{~m}$ long permanent sites (Ball Creek Above [BCA], Ball Creek Below [BCB], and Coweeta Creek [CC]) for population sampling, which should have contained the home ranges of most sculpin found within the sites (Petty and Grossman 2004). The three sites were located along a $\sim 1.5 \mathrm{~km}$ downstream gradient on Ball and Coweeta Creeks (approximate location $35.35^{\circ} \mathrm{N}, 83.25^{\circ} \mathrm{W}$ ) and ranged in elevation from $\sim 675 \mathrm{~m}(\mathrm{CC})$ to $\sim 695 \mathrm{~m}$ (BCA) (Appendix). We began our study in winter 1984 and terminated sampling in autumn 1995. Our study period encompassed some of the highest stream levels on record over the last 60 years in the Coweeta Creek drainage, and also included one of the harshest droughts (1985-1988). Consequently we conducted analyses on up to three separate data sets representative of the hydrologic variation observed during the course of the study: (1) all collections pooled (pooled), (2) drought years only (1985-1988, drought) and (3) non-drought years (1984, 1989-1995, non-drought).

\section{Habitat availability}

We collected data on physical habitat availability (Grossman and Ratajczak 1998), concurrently with spring and autumn population samples, beginning in autumn 1987, excluding 1991, and ending in 1995. We used a grid system and random number table to randomly select $3020 \times 20 \mathrm{~cm}$ quadrats in each site (see Grossman and Ratajczak 1998). Sampling was stratified so that each $10 \mathrm{~m}$ of bank length contained 10 randomly selected quadrats. Starting at the downstream border of each site, in each random quadrat we measured: (1) depth $( \pm 1 \mathrm{~cm}),(2)$ average velocity $( \pm 0.1$ $\mathrm{cm} / \mathrm{s}$, Marsh-McBirney [Frederick, Maryland, USA] Model 201 flow meter), and (3) a visual estimate of the percentage contribution to the total substratum of seven substratum classes based on maximum particle dimension (Grossman and Ratajczak 1998). These classes included: (1) bedrock (embedded substratum with a maximum dimension $>30 \mathrm{~cm}$ ), (2) boulder (unembedded substratum with a maximum dimension $>30$ $\mathrm{cm}),(3)$ cobble $(2.5-30 \mathrm{~cm}),(4)$ gravel $(0.2-2.5 \mathrm{~cm})$, (5) sand $<0.2 \mathrm{~cm}$, (6) silt (material capable of suspension in the water column), and (7) debris (organic material of any size). Average velocity for quadrats with depths $<75 \mathrm{~cm}$ was quantified with one measurement taken at 0.6 water column depth, whereas for quadrats $>75 \mathrm{~cm}$ in depth, average velocity was calculated as the mean of measurements made at $0.2 \times$ and $0.8 \times$ depth (Grossman and Freeman 1987).

To calculate sculpin density, beginning in 1987 we also measured the wetted area of the sites for each sampling period using seven transect measurements per site. We calculated estimates of wetted area for pre1987 samples, using regression analysis on mean daily flow $(X)$ and wetted area of a site $(Y)$ for 1987-1995 
data, and then inserted mean annualized daily flow measurements for 1984-1987 into this equation. The predictive ability of the equations for the three sites were: BCA, $r=0.62, P \ll 0.01$; BCB $, r=0.84, P \ll$ $0.01 ; \mathrm{CC}, r=0.81, P \ll 0.01$. Mean wetted areas $( \pm \mathrm{SD})$ for the sites during spring samples were: BCA, 133.1 $\pm 8.9 \mathrm{~m}^{2}$; $\mathrm{BCB}, 151.1 \pm 14.4 \mathrm{~m}^{2}$; and $\mathrm{CC}, 199.0 \pm$ $30.2 \mathrm{~m}^{2}$.

We quantified temporal changes in habitat availability by subjecting data from the random habitat availability quadrats to a principal component analysis (PCA, SAS Institute 1985) using the methods of Grossman et al. (1998). This analysis produced significant components (i.e., ecologically interpretable components with eigenvalues $>1.0$ ), which were then subjected to a variety of a posteriori analyses depending upon the hypothesis examined. First, we tested the null hypothesis that habitat availability within a site did not differ significantly between drought and non-drought periods for pooled spring and autumn samples. Previous work in this system has shown that null hypothesis testing (i.e., a test for no difference or effect) is ecologically appropriate for habitat availability, flow, and fish microhabitat use data (Grossman and Ratajczak 1998). We evaluated null hypotheses by calculating mean PC scores for the two periods (drought and non-drought) on all significant components and then testing for significant differences with a Wilcoxon test followed by nonparametric Tukey tests (Zar 1996, Grossman and Ratajczak 1998). We only report substratum differences $>2 \%$, because values below this are within our estimated margin of observer error (Grossman and Ratajczak 1998). Finally, we evaluated the stability of physical habitat characteristics of the three sites by comparing the number of seasons with significant within-site differences in drought and nondrought habitat availability comparisons.

In all analyses we set alpha to 0.1 to account for: (1) the inherent variability of long-term field data sets, (2) the uncontrollably low sample sizes of partitioned data sets (e.g., $n=4$ for drought samples), and (3) the fact that sculpin densities in Spring 1984-Spring 1987 data sets were estimated using regression-derived values for site area rather than actual measurements. Use of the 0.10 level for alpha is justified under certain limited circumstances (see Zar 1996, Grossman et al. 1998), and given the limitation of the data, we are less concerned about rejecting a true null hypothesis than failing to reject a false one.

\section{Flow variation (density-independent processes)}

We assessed the effects of variation in stream flow (density-independent variation) on sculpin via flow measurements from stream gages in both Ball Creek (Weir 9) and Shope Fork (Weir 8; see Plate 1), the two main tributaries of Coweeta Creek (Grossman et al. 1998). We used information from both weirs because they collect different data, all of which were necessary for analyses. Weir 8 provided data for parameters $1-$ 5, whereas Weir 9 provided data for parameters 6-11. Daily flows from the two weirs were highly correlated during the study (daily maximum flows, $r=0.94, P$ $\ll 0.01, N=4212$; daily minimum flows, $r=0.98, P$ $\ll 0.01, N=4212$ ). Weir data included: (1) highest maximum flow during the year (calendar year), (2) highest minimum flow during the year (calendar year), (3) mean monthly flow (calendar year), (4) mean monthly maximum flow (calendar year), (5) mean monthly minimum flow (calendar year), (6) maximum flow between spring and autumn for a given year, (7) maximum flow between autumn and the following spring, (8) maximum flow between spring and the following spring, (9) the number of high flows between spring and autumn of a given year, (10) the number of high flows between autumn and the following spring, and (11) the number of high flows between spring and the following spring.

Because the timing of high flow events determines their biological impact, we analyzed flow data in concordance with the life cycle of sculpin. Hence, we considered 1 April, the onset of the reproductive season of sculpin (DeHaven et al. 1992), to be the beginning of a water year, which then continued until collection of spring population samples the following year. We considered a flow event $>0.71 \mathrm{~m}^{3} / \mathrm{s}$ to be "high flow." These events had a recurrence interval of $>1$ per year (e.g., mean $=33$ high flow events [range 10-77] between 1 April and the following year's spring population sample) and hence, represent density-independent environmental variation that was regularly experienced by sculpin populations. Although the choice of a high flow level is somewhat arbitrary, $0.71 \mathrm{~m}^{3} / \mathrm{s}$ represents a compromise between base flows and extreme events such as 100-year floods that sculpin may rarely experience. Finally, setting $0.71 \mathrm{~m}^{3} / \mathrm{s}$ as "high flow" provided data sufficient for rigorous statistical testing, unlike flow events with less frequent recurrence intervals. We tested for differences in high flow events using a one-tailed Wilcoxon test $\left(H_{\mathrm{a}}\right.$ : fewer high flow events during the drought). This hypothesis was examined using three data sets: (1) full year, i.e., 1 April-31 March, (2) 1 April-autumn population sample, and (3) 1 October-spring population samples.

We quantified the relationship between flow variation and $r$ of sculpin by first conducting a PCA on annual estimates of 9 of the 11 flow measures described above; we omitted both maximum flow and the number of high flows between spring and autumn for a given year, to reduce multiple colinearity. We then included sample scores of these components in competing regression models (see Model construction and assessment). Principal component analysis was used because of correlations among flow variables used in the analysis. We also evaluated the effects of average flow conditions on sculpin by performing regression analysis on annualized mean daily flow values (Grossman 
et al. 1998) and the densities $(\log [n+1])$ of all lifehistory classes for pooled and partitioned data sets. Finally, because the drought data set may have been too small $(N=4)$ to detect the effects of low flows on sculpin demography, we also performed analyses on a "low flow" data set consisting of years with $<10$ high flow events $(N=7)$.

\section{Population sampling}

We sampled sculpin every other month between 1984 and 1987 (Freeman et al. 1988) and then reduced sampling to a single spring and autumn sample per year per site. The range of sampling dates for each site were as follows: (1) Ball Creek A, spring samples, 6 April to 13 June (7 of 12 in May), autumn samples, 26 July to 10 November (7 of 12 in September); (2) Ball Creek B, spring samples, 28 April to 31 May, autumn samples 16 August to 2 November (9 of 12 in September); (3) Coweeta Creek, spring samples, 26 April to 25 May, autumn samples, 19 August to 2 November (9 of 12 in September). We used the sampling methodology of Freeman et al. (1988), which involved three sequential electrofishing passes (Smith-Root [Vancouver, Washington, USA] Model 11A electrofisher) of constant effort through a site that was block-netted (4.8-mm bar mesh) at both ends. The bottoms of block nets were anchored with a layer of substratum to prevent escape of fish from the site. Stunned fish were netted immediately and placed in an aerated container. After completion of a pass, all specimens were counted, individually measured (standard length, to the nearest millimeter), and weighed (electronic balance, $\pm 0.01 \mathrm{~g}$ ). Each site was sampled on a single day and all sculpin were then evenly redistributed throughout the site.

We used a three-pass depletion estimator (Program Capture; White et al. 1982) to derive abundance estimates for the total population and each life-history class separately (YOY, juveniles, adults). We generally did not present results for adults because they dominated the population and displayed patterns essentially identical to those for the total population. Abundance estimates were converted to densities using site area measurements described previously. We derived annual density estimates for the population and juveniles from spring samples because separation of these life-history classes was most distinct during this period (Appendix: Fig. A1), and the effects of winter floods (i.e., densityindependent mortality) would be most visible at this time (Erman et al. 1988). We estimated YOY densities using autumn samples because most recruitment had occurred by this season (G. D. Grossman, unpublished data).

Recent work has shown that sampling variance can produce underestimates of true population sizes when the three-pass depletion estimator is used (Peterson et al. 2004). However, sample variances were uncorrelated with sample means for two of three sites and the correlation for the third site only was significant when a single, highly leveraged point was included. In addition, population estimates were similar to those obtained via mark-recapture studies conducted with snorkeling (Petty 1998). Consequently, we believe our population estimates were not strongly influenced by sampling biases described by Peterson et al. (2004).

We tested for drought effects by comparing sculpin density estimates for drought and non-drought samples with a one-tailed Wilcoxon test. Given the high stability of these populations (Grossman et al. 1990) and previous results on a paucity of drought-non-drought differences in the system (Grossman and Ratajczak 1998, Grossman et al. 1998), a null hypothesis testing approach (Burnham and Anderson 2002) was appropriate. We also examined potential drought effects on the size structure of sculpin populations by comparing the proportion of juveniles and adults in pooled annual drought and non-drought samples using a chi-square test. Finally, we compared mean length and mass of the life-history classes in drought and non-drought samples (Wilcoxon test) to identify more subtle drought effects.

\section{Model construction and assessment}

We assessed the relative impacts of density-dependent (DD), density-independent (DI), and recruitment limitation (RL) processes on sculpin by constructing a priori models capable of explaining variation in the per capita rate of change, $r=\ln \left(n_{t+1} / n_{t}\right)$, of these populations. Although model selection can have an element of arbitrariness, our models were based on simple and complex relationships (see Table 1) between $r$ and various population parameters documented in the literature (Murdoch 1994, Hixon et al. 2002). Consequently, our models all have a biologically realistic, a priori basis and do not represent data mining (sensu Burnham and Anderson 2002).

We evaluated models using the information-theoretic approach of Burnham and Anderson (2002), which allows one to evaluate the plausibility of competing explanatory models (i.e., use a strong inference approach [Platt 1964]). First, we constructed individual global regression models for the population, juvenile, and YOY life-history classes in each site, which included all biologically relevant processes. From each global model, we constructed up to 13 (varied by life-history class) candidate models that contained combinations of the process variables (see Table 1). Candidate models were fit to the data using linear regression (Neter et al. 1996). We assessed the fit of candidate models using AIC adjusted for small samples (i.e., AICC) (Burnham and Anderson 2002). Akaike's Information Criterion measures the amount of information loss (i.e., entropy) in each candidate model with the best-fitting model having the lowest AICC (i.e., the lowest information loss). We evaluated candidate models by their $\Delta$ AIC weights (i.e., $w_{i}$ values), which range from 0 (complete information loss) to 1.0 (no information loss). The $W_{i}$ 
TABLE 1. Candidate models used to evaluate the relative importance of the processes affecting $r$ for sculpin population and life-history classes.

\begin{tabular}{|c|c|}
\hline Process & Models \\
\hline $\begin{array}{l}\text { Global model: density dependence, delayed density dependence, complex density } \\
\text { dependence, density independence and recruitment limitation }\end{array}$ & $\begin{array}{l}\text { RPOP }=\text { dpop, djuv, dyoy, dpop } \text { d }_{t-1}, \\
\text { PCA1, PCA2 }\end{array}$ \\
\hline $\begin{array}{l}\text { Simple density dependence (DD): intraspecific competition for food or space in } \\
\text { year } t \text { limits } r \text { for population (or life-history class) increase (i.e., } r=1 \mathrm{n} t / t- \\
\text { 1) }\end{array}$ & $\mathrm{DD}=\mathrm{RPOP}=-\mathrm{dpop}$ \\
\hline $\begin{array}{l}\text { Delayed simple density dependence (DDD): intraspecific competition for food or } \\
\text { space in previous year limits } r \text { for population (or life-history class) }\end{array}$ & $\mathrm{DDD}=\mathrm{RPOP}=-\mathrm{dpop}_{t-1}$ \\
\hline $\begin{array}{l}\text { Complex density dependence (time delayed) (CDD): intraspecific competition for } \\
\text { food or space limits } r \text { for population (or life-history class) via independent } \\
\text { negative effects of multiple life-history classes }\end{array}$ & $\begin{array}{l}\mathrm{CDD}=\mathrm{RPOP}=- \text { dpop, }- \text { djuv, } \\
\quad-\text { dyoy }\end{array}$ \\
\hline $\begin{array}{l}\text { Simple density independence (DI): high density-independent mortality produced } \\
\text { by harsh conditions during high flow years limits } r \text { or high, density-indepen- } \\
\text { dent survivorship produced by favorable physical conditions during high flow } \\
\text { years limits } r \text { for population (or life-history class). }\end{array}$ & $\begin{array}{l}\mathrm{DI}=\mathrm{RPOP}=- \text { or }+\mathrm{PCA} 1 \\
\mathrm{DI}=\mathrm{RPOP}=- \text { or }+\mathrm{PCA} 2\end{array}$ \\
\hline $\begin{array}{l}\text { Complex density independence (CDI): high density-independent mortality pro- } \\
\text { duced via a complex of harsh physical conditions (e.g., both PCA1 and PCA2) } \\
\text { during high flow years limits } r \text { for population (or life-history class), or high, } \\
\text { density-independent survivorship produced by a complex of favorable physical } \\
\text { conditions (e.g., both PCA1 PCA2) during high flow years limits } r \text { for popula- } \\
\text { tion (or life-history class) }\end{array}$ & $\begin{array}{l}\mathrm{CDI}=\mathrm{RPOP}=- \text { or }+\mathrm{PCA} 1 \\
\quad \mathrm{PCA} 2\end{array}$ \\
\hline $\begin{array}{l}\text { Simple recruitment limitation (RL): } r \text { for population (or life-history class) in } \\
\text { year } X \text { is limited by density (recruits) of younger life-history class in year } X \\
-1 \text { or } X-2 \text {. }\end{array}$ & $\begin{array}{l}\mathrm{RL}=\mathrm{RPOP}=\operatorname{djuv}_{t-1} \\
\mathrm{RL}=\mathrm{RPOP}=\text { dyoy }_{t-2}\end{array}$ \\
\hline $\begin{array}{l}\text { Complex multiprocess models (MM): multiple processes act independently on } r \\
\text { for population or life-history class }\end{array}$ & $\begin{array}{l}\text { CDD, CDI, RL = RPOP = dpop, } \\
\text { djuv }_{t-1}, \text { dyoy }_{t-2}, \text { PCA } 1, \text { PCA2 } \\
\text { CDD, CDI, RL }=\text { RPOP = dpop, } \\
\text { djuv }_{t-1}, \text { PCA } 1, \text { PCA2 } \\
\text { CDD, CDI, RL = RPOP = dpop, } \\
\text { dyoy } \text {. }_{t-2}, \text { PCA1, PCA2 } \\
\text { DD, CDI }=\text { RPOP }=\text { dpop, PCA1, } \\
\text { PCA2 }\end{array}$ \\
\hline
\end{tabular}

Notes: The processes are derived from the literature or previous studies on sculpin. To reduce redundancy, we only list models for RPOP, but similar models were run for each life-history class with the appropriate substitutions (e.g., DD RJUV = -djuv). We evaluated candidate models using AIC (see Methods). Abbreviations are as follows: RPOP, $r$ for population; RJUV, $r$ for juveniles; RYOY, $r$ for young-of-the-year; dpop ${ }_{t}$, population density in year $t$ (djuv, dyoy, etc.); PCA1 and PCA2, sample scores on PC1 and PC2, respectively.

value actually represents the posterior probability that a given model is true, given the data and the set of competing candidate models (Burnham and Anderson 2002). The "truth value" of different candidate models can be evaluated by dividing the $w_{i}$ value of the model with the highest $w_{i}$ by the $w_{i}$ value of any model with a lower value. The result is the comparative likelihood that, given the data, the best model (highest $w_{i}$ value) is true in comparison to any model with a lower $w_{i}$ (e.g., best model is 6.4 times more likely to be true than model $Y$ [Burnham and Anderson 2002]). By convention, we did not interpret models that had $w_{i}$ values that were $<10 \%$ of the model with the highest $w_{i}$ (Burnham and Anderson 2002).

We incorporated model selection uncertainty in analyses of the predictor variables of interpretable models (i.e., those with $\Delta \mathrm{AIC}$ weights $>10 \%$ of the best model) by calculating model-averaged estimates $(\beta$; Burnham and Anderson 2002) for individual coefficients (and standard errors) using $\triangle \mathrm{AIC}$ weights (Buckland et al. 1997). We estimated the relative importance of predictor variables by summing their $\Delta \mathrm{AIC}$ weights over all interpretable models. To assess the precision of model-averaged coefficients, we calculated $95 \%$ confidence limits for these coefficients using a $t$ statistic with $n-1$ df. Coefficients whose confidence limits included 0 were viewed as having equivocal "truth" value.

We calculated per capita rates of change $(r)$ for the population, juvenile, and YOY life-history classes, as $r=\ln \left(N_{t} / N_{t-1}\right)$, where $N_{t}$ represents density for a lifehistory class at time $t$ (Cappuccino and Price 1995). Because biological reality necessitated different estimation strategies for the population and juveniles (spring estimates) vs. YOY (fall estimates), when YOY were entered in a model they represented the estimate for the previous fall, unless otherwise identified with a subscript. Calculation of RYOY ( $r$ for young-of-theyear) was based on the current year's autumn sample divided by the previous autumn's sample.

Preliminary time-series analysis (Box and Jenkins 1976) demonstrated that $r$ values were unrelated to population densities at time lags longer than two years, and we have therefore restricted our analyses of density effects on current population growth to densities at times $t-1$ and $t-2$. To deal with spurious density 
dependence produced by autocorrelations in the data set, we also tested for simple density dependence using the parametric bootstrap likelihood ratio test of Dennis and Taper (1994). Sample number was 1000 , and we set $P$ at 0.10 due to the small number of samples in the sculpin data series (Zar 1996) and the loss of rigor experienced by maximum likelihood estimation with small, non-asymptotic samples (Stuart and Ord 1991). Although the Dennis and Taper method can overestimate density dependence when coefficients of variation of sampling variability are $>35 \%$ (Shenk et al. 1998), mean $\mathrm{CV}$ values for sampling variability in individual samples for $\mathrm{BCA}, \mathrm{BCB}$, and $\mathrm{CC}$ ranged from $11 \%$ to $15 \%$. Consequently, it is unlikely that the Dennis and Taper test produced biased results (Dennis and Otten 2000).

Given the relative proximity of our sites, we suspected that the temporal dynamics of sculpin populations in these sites might be correlated. Consequently, we ran two series of simple pairwise correlation tests ( $r$, with $P$ adjusted by Sidak's multiplicative inequality [SAS 1985]): (1) between the $r$ values of each lifehistory class among sites, and (2) between the densities of each life-history class among sites. Because none of these correlations was significant, it was possible to use all variables in model construction.

\section{Removal experiment}

As a direct assessment of the potential effects of density dependence (i.e., intraspecific competition for microhabitat) on sculpin, we conducted a removal experiment in four 150-m stream reaches, two on Shope Fork and two on Ball Creek (Appendix: Fig. A2). The physical characteristics of these sites resembled those of BCA and BCB. The sites were separated by at least $200 \mathrm{~m}$ and were very similar geomorphologically (i.e., similar depths and velocities and pool, run, riffle sequences). We randomly selected one site on each stream as a removal site and left the other as a control. The experiment consisted of four phases: (1) a pre-removal two-week period of microhabitat observations on sculpin that served as a within-site control, (2) three-pass electrofishing of all sites to estimate adult and juvenile abundances using the depletion estimator (see Population sampling), which also served as a method of adult removal from treatment sites, followed by a fourday acclimation period, (3) a second two-week period of microhabitat observations to test for microhabitat shifts in the absence of adults, and (4) a final electrofishing of the site to estimate final abundances of adult and juvenile sculpin.

In phase one of the experiment we made microhabitat measurements on sculpin by snorkeling each site two times over five days in early August 1998 (methods of Grossman and Ratajczak 1998). Upon locating a sculpin, we marked its focal position with a painted lead weight, visually estimated its standard length, and classified individuals as juveniles $(<3.2-4.9 \mathrm{~cm})$, small
TABle 2. Comparison of the number of high flow events between drought (1985-1988) and non-drought (1984, 1989-1995) periods for the three study sites.

\begin{tabular}{lcc}
\hline \hline $\begin{array}{c}\text { Site } \\
\text { (by period) } \dagger\end{array}$ & Non-drought samples & Drought samples \\
\hline Spring-autumn & & \\
BCA & 14.0 & $4.5^{*}$ \\
BCB & 13.4 & $4.3^{*}$ \\
CC & 13.4 & $4.3^{*}$ \\
Autumn-spring & & \\
BCA & 32.1 & $10.7^{* *}$ \\
BCB & 32.1 & $11.3^{*}$ \\
CC & 32.3 & $11.3^{*}$ \\
\hline
\end{tabular}

Note: The values differ slightly because of slight differences in the timing of sampling at the three sites.

$* P<0.05 ; * * P<0.01$; one-tailed Wilcoxon test.

$\dagger \mathrm{BCA}=$ Ball Creek Above, BCB = Ball Creek Below, $\mathrm{CC}=$ Coweeta Creek

adults $(5.0-6.5 \mathrm{~cm})$, or large adults $(>6.5 \mathrm{~cm})$ on the basis of body size. After completing a snorkeling pass, we quantified microhabitat characteristics (i.e., depth, average and bottom velocity, and the percentage composition of seven substratum categories in a $20 \times 20$ $\mathrm{cm}$ quadrat) at each individual's focal position. Measurement techniques were previously described in the section on Habitat availability.

To test for niche shifts microhabitat use we conducted a PCA on each set of microhabitat use data (see Grossman and Freeman 1987, Grossman and Ratajczak 1998) and then calculated mean scores on PC1 for each size class of sculpin in pre- and post-removal samples. We tested for the presence of microhabitat shifts by examining 95\% confidence intervals for mean PC1 scores for each size class of sculpin in pre- and postremoval samples. We considered a microhabitat shift to have occurred if the $95 \%$ CI did not overlap the mean of the pre-removal sample.

\section{RESULTS \\ Habitat availability}

Flow variation.-Drought affected flow regimes in the Coweeta drainage, and there were significantly fewer high flow events during this period (Table 2). The PCA identified two patterns of flow variation $(89 \%$ variance explained) during the study (Fig. 1). In general, drought samples had both low mean flows and few high flow events (Fig. 1). The sole exception was 1986, during which there were low overall flows coupled with several extremely high flow events. Non-drought samples fell in two clusters, one group with high overall flows and little variation between low and high flow periods $(1989,1990,1992,1994)$ and a second group that tended to have slightly higher mean flow conditions with few high flow events $(1984,1991,1993)$ (Fig. 1).

Among-site comparisons.-The habitat characteristics of the three sites differed during both drought and 


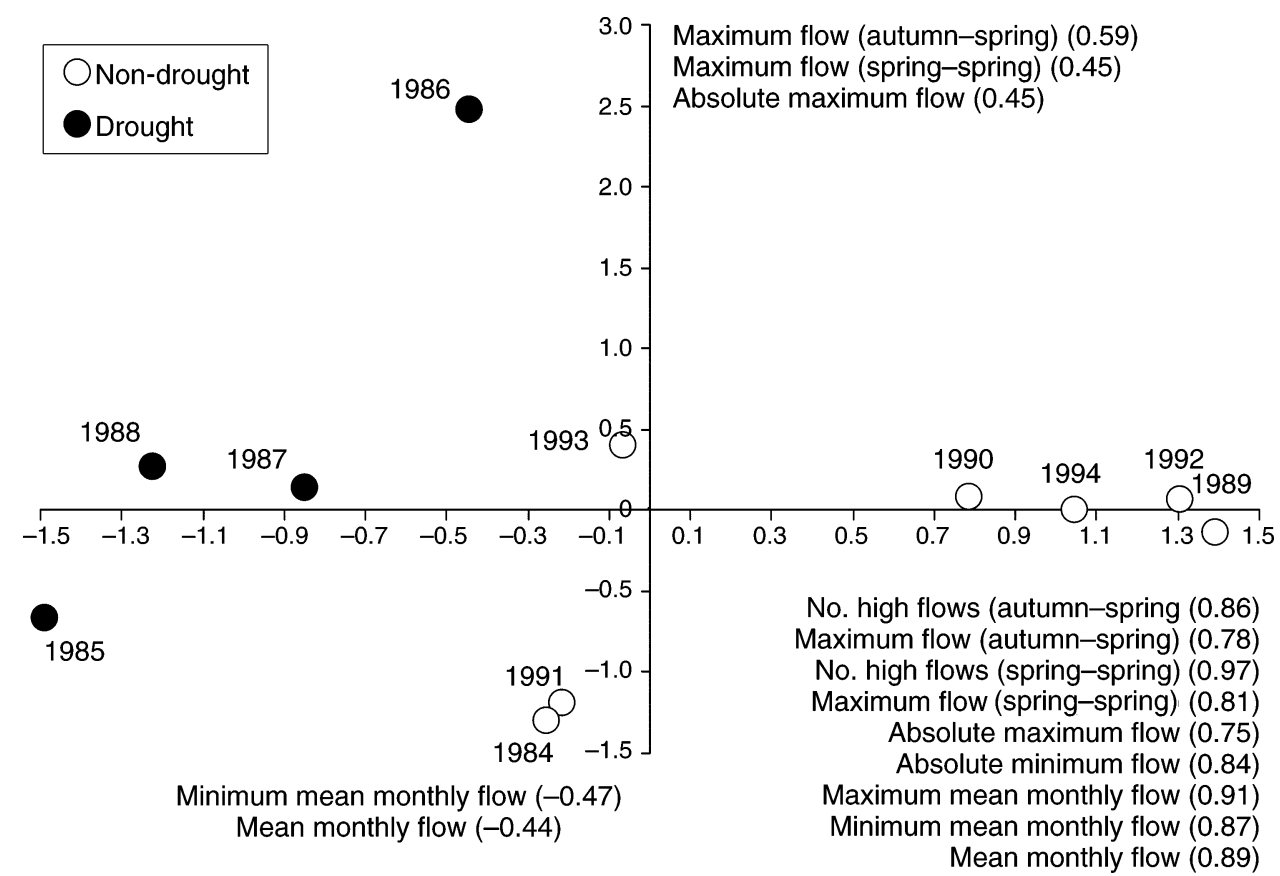

FIG. 1. Results for PCA for Coweeta Creek drainage flow data. Variables are listed below the axis with their loading in parentheses. Data for drought and non-drought periods for mean flow, mean maximum, and mean minimum flows are as follows: mean flow, non-drought $0.28 \mathrm{~m}^{3} / \mathrm{s}$, drought $0.17 \mathrm{~m}^{3} / \mathrm{s}$; mean maximum flow, non-drought $0.36 \mathrm{~m}^{3} / \mathrm{s}$, drought $0.22 \mathrm{~m}^{3} / \mathrm{s}$; mean minimum flow, non-drought $0.25 \mathrm{~m}^{3} / \mathrm{s}$, drought $0.17 \mathrm{~m}^{3} / \mathrm{s}$. Data are from Weir 8 .

non-drought periods (Table 3 ). In general, $\mathrm{CC}$ was the deepest and fastest site, with greater amounts of boulder and less depositional substrata than the other sites. $\mathrm{BCA}$ and $\mathrm{BCB}$ were the most similar sites, differing only in velocity and cobble (BCA faster, more cobble) and two other minor substratum types (Table 3 ).

Within-site comparisons.-

1. Ball Creek Above.-Both the PCAs of pooled seasonal samples (spring and autumn) and autumn samples alone indicated that BCA had lower average velocity, slightly shallower depth, and more silt during the drought (Table 4). Spring samples produced no detectable habitat differences between drought and nondrought samples (Table 4).

2. Ball Creek Below.-Pooled samples indicated that there were substantial changes in the site between drought and non-drought years (Table 4; [PC3 and PC4 were gravel components with identical results, so only PC3 is described.]) Pooled samples indicated that the site was shallower with lower mean velocity and more gravel, and less cobble and boulder during the drought than in the non-drought years (Table 4). Spring samples yielded no significant components, whereas autumn samples extracted two components that elucidated drought-non-drought differences similar to those observed for pooled data (Table 4).

3. Coweeta Creek.-Analyses of pooled samples produced significant differences between drought and non-drought years on components 1 and 2, and the site was slightly shallower with lower mean velocity and more gravel during the drought than in non-drought seasons (Table 4). Spring samples showed that the site was shallower with lower mean velocity during the drought (Table 4). Autumn samples indicated that drought samples were shallower with lower mean velocity, more gravel and silt, and less cobble than nondrought samples (Table 4).

In summary, BCA appeared to have the greatest physical stability because it displayed the fewest seasonal differences in habitat availability between drought and non-drought years (Table 4). By contrast, $\mathrm{CC}$ displayed the greatest number of significant seasonal differences in habitat availability (pooled, spring, or autumn; Table 4), and hence was the least stable site. Results for BCB were intermediate, although withinseason analyses for pooled data actually yielded more significant differences than those detected for CC.

\section{Population processes}

\section{Ball Creek Above.-}

1. Density and population stability.-Despite substantial environmental variability, the sculpin population in BCA was highly stable (Fig. 2) and displayed very low $\mathrm{CV}$ values for both population density (0.23) and abundance (0.26) data. Program Capture indicated that none of the total population estimates violated the assumptions of the three-pass depletion method, and $95 \%$ confidence intervals for density estimates were relatively low, ranging from 0.1 to $0.6 \mathrm{~m}^{2}$. A comparison of drought vs. non-drought samples also indicated 
TABLE 3. Habitat availability data under drought and non-drought conditions in the three sites; values are means with SD in parentheses.

\begin{tabular}{|c|c|c|c|c|c|c|}
\hline \multirow[b]{2}{*}{ Site } & \multirow[b]{2}{*}{ Depth $(\mathrm{cm})$} & \multirow{2}{*}{$\begin{array}{l}\text { Mean } \\
\text { velocity } \\
(\mathrm{cm} / \mathrm{s})\end{array}$} & \multicolumn{4}{|c|}{ Substrate composition (\%) } \\
\hline & & & Bedrock & Boulder & Cobble & Gravel \\
\hline BCA non-drought & $14.6(8.6)$ & $36(27)$ & $1(7)$ & $11(22)$ & $54(28)$ & $14(13)$ \\
\hline BCA drought & $13.3(6.8)$ & $25(19)$ & $2(6)$ & $5(13)$ & $53(25)$ & $16(18)$ \\
\hline $\mathrm{BCB}$ non-drought & $14.9(7.0)$ & $28(23)$ & $2(8)$ & $13(22)$ & $50(27)$ & $13(15)$ \\
\hline BCB drought & $12.8(6.5)$ & $13(14)$ & $3(11)$ & $8(17)$ & $46(27)$ & $17(17)$ \\
\hline CC non-drought & $20.1(11.9)$ & $42(30)$ & $2(13)$ & 19 (29) & $51(30)$ & $11(13)$ \\
\hline CC drought & $16.4(9.7)$ & $22(19)$ & 1 (4) & $20(29)$ & $48(28)$ & $15(15)$ \\
\hline
\end{tabular}

that there were no significant differences in the proportion of the population composed of either adults (non-drought $[\mathrm{ND}]=0.76$, drought $[\mathrm{DR}]=0.69 ; P=$ $0.50)$ or juveniles (ND $=0.22$, $\mathrm{DR}=0.22 ; P=0.87$ ) during these periods. We also failed to detect significant differences in the densities of the population (ND = 0.36 sculpin $\left./ \mathrm{m}^{2}, \mathrm{DR}=0.34 \mathrm{sculpin} / \mathrm{m}^{2} ; P=0.43\right)$, adults $\left(\mathrm{ND}=0.27 \mathrm{sculpin} / \mathrm{m}^{2}, \mathrm{DR}=0.24 \mathrm{sculpin} / \mathrm{m}^{2}\right.$; $P=0.31$ ), juveniles $\left(\mathrm{ND}=0.08 \mathrm{sculpin} / \mathrm{m}^{2}, \mathrm{DR}=\right.$ 0.08 sculpin $/ \mathrm{m}^{2} ; P=0.47$ ) or YOY (ND $=0.15$ scul$\left.\mathrm{pin} / \mathrm{m}^{2}, \mathrm{DR}=0.06 \mathrm{sculpin} / \mathrm{m}^{2} ; P=0.12\right)$ between drought and non-drought samples.

Partitioned analyses of density data in BCA demonstrated that YOY densities were strongly positively correlated with annualized mean daily flows during drought years and negatively correlated during nondrought years (Fig. 3). This hump-shaped curve indicated that intermediate flows produced the highest recruitment of YOY.

2. Sculpin per capita rate of change.-Per capita rate of change data indicated that sculpin in BCA were affected by multiple processes, with simple density dependence (DD) playing the dominant role (Tables 5 and 6). Given the data, the simple density-dependence model (DD) had the greatest explanatory power for all lifehistory classes, and was approximately 6, 5, and 7 times more likely to be true than the second best fitting model (Table 5). For population data, complex density dependence (CDD) also was included in the set of interpretable models; however, the $95 \%$ CI for the model's

TAble 4. Differences (Wilcoxon test) in mean PC scores of habitat availability data within sites between periods (D, ND).

\begin{tabular}{|c|c|c|c|c|c|c|}
\hline \multirow{2}{*}{$\begin{array}{l}\text { Site and } \\
\text { data set }\end{array}$} & \multirow{2}{*}{$\begin{array}{l}\mathrm{PC} \\
\text { axis }\end{array}$} & \multirow{2}{*}{$\begin{array}{c}\text { Variance } \\
\text { explained } \\
(\%)\end{array}$} & \multicolumn{2}{|c|}{ Loading $>0.40 \dagger$} & \multirow[b]{2}{*}{$P$} & \multirow{2}{*}{$\begin{array}{l}\text { Microhabita } \\
\text { availability }\end{array}$} \\
\hline & & & Variable & Loading & & \\
\hline BCA Pooled & 1 & 27 & $\begin{array}{l}\text { velocity } \\
\text { depth }\end{array}$ & $\begin{array}{l}0.82 \\
0.56\end{array}$ & 0.06 & $\mathrm{ND}>\mathrm{D}$ \\
\hline BCA Autumn & 1 & 27 & $\begin{array}{l}\text { silt } \\
\text { sand } \\
\text { velocity } \\
\text { cobble } \\
\text { depth }\end{array}$ & $\begin{array}{r}-0.72 \\
-0.45 \\
0.83 \\
0.64 \\
0.55\end{array}$ & $\ll 0.01$ & $\mathrm{ND}>\mathrm{D}$ \\
\hline \multirow[t]{3}{*}{ BCB Pooled } & 1 & 26 & $\begin{array}{l}\text { velocity } \\
\text { cobble } \\
\text { gravel } \\
\text { depth }\end{array}$ & $\begin{array}{l}0.77 \\
0.56 \\
0.47 \\
0.55\end{array}$ & $\ll 0.01$ & $\mathrm{ND}>\mathrm{D}$ \\
\hline & 2 & 15 & $\begin{array}{l}\text { cobble } \\
\text { boulder }\end{array}$ & $\begin{array}{r}-0.66 \\
0.91\end{array}$ & 0.02 & $\mathrm{ND}>\mathrm{D}$ \\
\hline & 3 & 14 & gravel & 0.41 & $\ll 0.01$ & $\mathrm{D}>\mathrm{ND}$ \\
\hline BCB Autumn & 1 & 22 & $\begin{array}{l}\text { velocity } \\
\text { cobble }\end{array}$ & $\begin{array}{l}0.70 \\
0.56\end{array}$ & $<0.01$ & $\mathrm{ND}>\mathrm{D}$ \\
\hline \multirow[t]{2}{*}{ CC Pooled } & 1 & 25 & $\begin{array}{l}\text { velocity } \\
\text { depth }\end{array}$ & $\begin{array}{l}0.86 \\
0.65\end{array}$ & $\ll 0.01$ & $\mathrm{ND}>\mathrm{D}$ \\
\hline & 2 & 19 & gravel & 0.50 & $<0.06$ & $\mathrm{D}>\mathrm{ND}$ \\
\hline CC Spring & 1 & 24 & $\begin{array}{l}\text { velocity } \\
\text { depth }\end{array}$ & $\begin{array}{l}0.86 \\
0.68\end{array}$ & $<0.04$ & $\mathrm{ND}>\mathrm{D}$ \\
\hline \multirow[t]{2}{*}{ CC Autumn } & 1 & 27 & $\begin{array}{l}\text { silt } \\
\text { velocity }\end{array}$ & $\begin{array}{r}-0.74 \\
0.82\end{array}$ & $<0.08$ & $\mathrm{ND}>\mathrm{D}$ \\
\hline & 3 & 13 & gravel & 0.64 & $<0.01$ & $\mathrm{D}>\mathrm{ND}$ \\
\hline
\end{tabular}

Notes: Redundant components were not reported (i.e., multiple components with the same loading). Pooled data sets include both spring and autumn samples.

$\dagger$ Loading on significant components (PC axes). Variables are average velocity, depth, and percentage composition of silt, sand, gravel, cobble, and boulders.

Significant differences in habitat availability between periods are shown. 


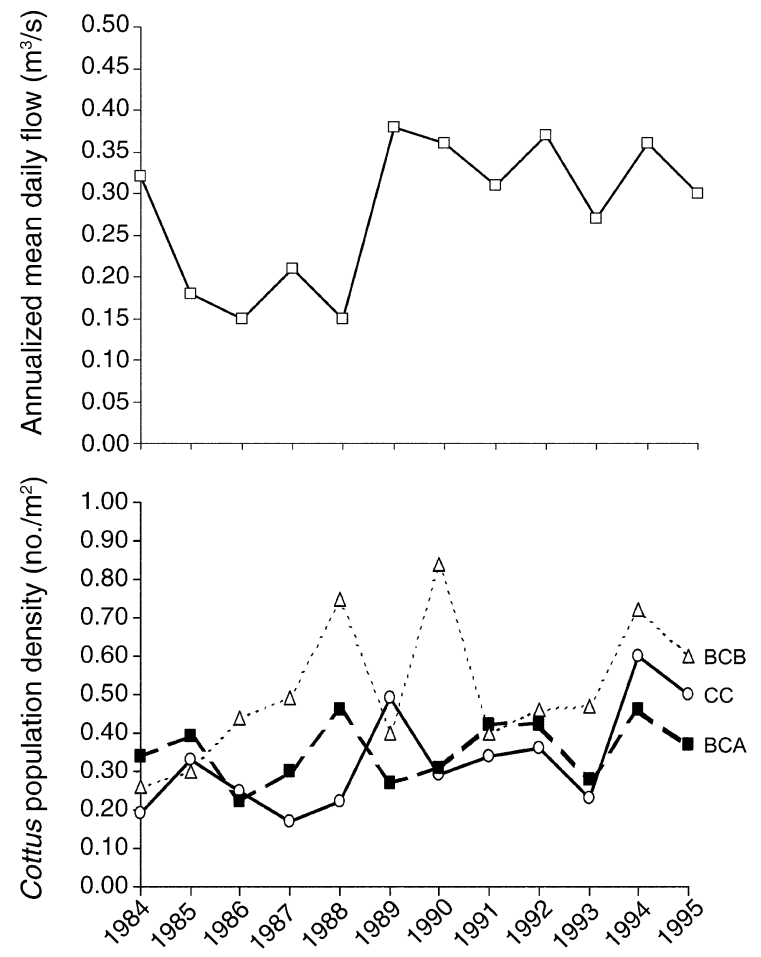

FIG. 2. Annualized mean daily flow values for the study period (top panel) and population density estimates (bottom panel) for sculpin in the three sites.

CDD term included zero (Table 6). Juveniles displayed the greatest number of interpretable models (including positive DI and several DD models), although the only model parameter estimate that did not overlap zero was djuv (DD) (Tables 5 and 6). Consequently, the explanatory power of all models with the exception of djuv DD was low (Tables 5 and 6). Patterns for YOY indicated that DD provided the greatest explanatory power for per capita rate of change data, with both positive and negative DI factors playing a much smaller explanatory role. Tests for DD using the Dennis and Taper method also detected DD in all three life-history classes (population, $b=-1.251, P<0.03$; juveniles, $b=$ $-1.337, P<0.01$; YOY, $b=-1.463, P<0.01)$. Partitioned data sets did not produce any significant relationships for any life-history class.

Ball Creek Below.-

1. Density and population stability.-The stability of the sculpin population in BCB also was high, with both population density and abundance coefficients of variation equaling 0.36 and 0.33 , respectively. As with $\mathrm{BCA}$, none of the total population estimates violated the assumptions of the three-pass depletion method, and asymmetric 95\% confidence intervals for density estimates ranged from 0.1 to $2.5 \mathrm{sculpin} / \mathrm{m}^{2}$. This range was strongly affected by a single annual confidence interval that ranged from 1.1 to $3.5 \mathrm{sculpin} / \mathrm{m}^{2}$. There were no significant differences during drought and nondrought years in the proportion of the population com- posed of either adults $(\mathrm{ND}=0.68, \mathrm{DR}=0.43 ; P=$ 0.17 ) or juveniles (ND $=0.29, \mathrm{DR}=0.55 ; P=0.13)$. Nonetheless, adult densities were significantly lower during the drought than in non-drought years (ND = 0.34 sculpin $\left./ \mathrm{m}^{2}, \mathrm{DR}=0.19 \mathrm{sculpin} / \mathrm{m}^{2} ; P=0.03\right)$, although this trend was not observed in the population $\left(\mathrm{ND}=0.52 \mathrm{sculpin} / \mathrm{m}^{2}, \mathrm{DR}=0.50 \mathrm{sculpin} / \mathrm{m}^{2} ; P \gg\right.$ $0.05)$, juveniles $\left(\mathrm{ND}=0.16 \mathrm{sculpin} / \mathrm{m}^{2}, \mathrm{DR}=0.29\right.$ sculpin $\left./ \mathrm{m}^{2} ; P>0.05\right)$, or YOY (ND $=0.10 \mathrm{sculpin} / \mathrm{m}^{2}$, $\mathrm{DR}=0.16$ sculpin $\left./ \mathrm{m}^{2} ; P \gg 0.05\right)$.

2. Sculpin per capita rate of change.-Per capita rate of change for sculpin in BCB was best explained by one single-factor model per life-history class (Tables 5 and 6). Given the observed patterns in the data, the most plausible explanatory models for population and juvenile life-history classes were DD models (dpop and djuv), whereas the most plausible model for YOY data was negative DI produced by high flows (Tables 5 and 6). Results from the Dennis and Taper analysis were similar, except that DD was found for all three life-history classes (population, $b=-0.893, P<0.06$; juveniles, $b=0.905, P<0.03$; YOY, $b=-0.974, P$ $<0.10)$.

Partitioned data sets offered evidence that DD may influence YOY densities in BCB during low water years. For example, during the drought, autumn densities of YOY were inversely correlated with spring densities of both the population $(Y=-0.67 X+0.49$, $\left.n=4, r^{2}=0.84, P=0.09\right)$, and juveniles $(Y=-0.80 X$ $\left.+0.39, n=4, r^{2}=0.99, P=0.005\right)$. The juvenileYOY interaction may be a general feature of low water periods in $\mathrm{BCB}$, because it also was present in years with $<10$ high flow events in BCB (Fig. 4).

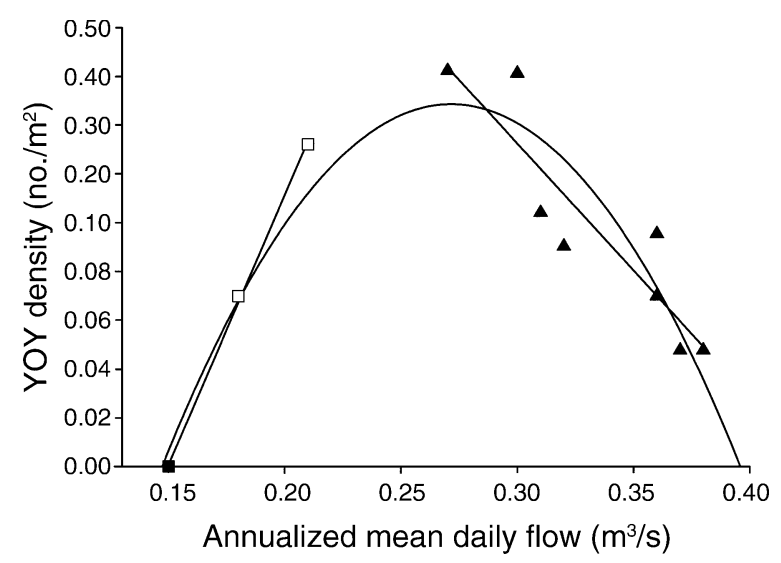

FIG. 3. The relationship between YOY density in BCA and annualized mean daily flows (Weir 8) during both nondrought years. Squares represent data from drought years $(n$ $=4)$ and the triangles represent non-drought years $(n=8)$. The solid square represents two data points. Line equations are as follows: parabola $Y=168.4 X+818.5 X^{2}-7.2, r^{2}=$ 0.89 ; drought data (squares) $Y=22.1 X-3.3, r^{2}=0.99$; non-drought data (triangles) $Y=10.4 X+4.8, r^{2}=0.83$. 
TABle 5. Model evaluation statistics for all sites and life-history classes.

\begin{tabular}{|c|c|c|c|c|}
\hline $\begin{array}{l}\text { Response } \\
\text { variable, } \\
\text { by site }\end{array}$ & Candidate model (process) & $\mathrm{AIC}_{\mathrm{C}}$ & $\Delta \mathrm{AIC}_{\mathrm{C}}$ & $w_{i} \dagger$ \\
\hline \multicolumn{5}{|l|}{$\overline{\mathrm{BCA}}$} \\
\hline \multirow[t]{2}{*}{ RPOP } & -dpop (DD) & 6.252 & 0.000 & 0.851 \\
\hline & $-\mathrm{dpop},-\mathrm{dpop}_{t-1}(\mathrm{CDD})$ & 9.956 & 3.704 & $0.134(6.3 \times)$ \\
\hline \multirow[t]{4}{*}{ RJUV } & $-\operatorname{djuv}(\mathrm{DD})$ & 44.167 & 0.000 & 0.577 \\
\hline & PCA1 (DI+) & 47.251 & 3.084 & $0.123(4.7 \times)$ \\
\hline & -dpop (DD) & 47.426 & 3.359 & $0.074(7.8 \times)$ \\
\hline & - dyoy $_{t-1}$ (DD) & 48.473 & 4.306 & $0.067(8.6 \times)$ \\
\hline \multirow[t]{3}{*}{ RYOY } & -dyoy (DD) & 45.934 & 0.000 & 0.630 \\
\hline & PCA2 (DI+) & 49.904 & 3.967 & $0.086(7.3 \times)$ \\
\hline & -PCA1 (DI-) & 50.081 & 4.146 & $0.079(7.8 \times)$ \\
\hline \multicolumn{5}{|l|}{$\mathrm{BCB}$} \\
\hline RPOP & -dpop (DD) & 9.337 & 0.000 & 0.967 \\
\hline RJUV & -djuv (DD) & 32.642 & 0.000 & 0.982 \\
\hline RYOY & PCA1 (DI-) & 35.507 & 0.000 & 0.919 \\
\hline \multicolumn{5}{|l|}{$\mathrm{CC}$} \\
\hline \multirow[t]{6}{*}{ RPOP } & PCA1 (DI+) & 19.854 & 0.000 & 0.310 \\
\hline & dyoy $_{t-2}(\mathrm{RL})$ & 20.064 & 0.210 & $0.278(1.1 \times)$ \\
\hline & -dpop (DD) & 20.540 & 0.686 & $0.219(1.4 \times)$ \\
\hline & $\operatorname{djuv}_{t-1}(\mathrm{RL})$ & 21.903 & 2.050 & $0.111(2.8 \times)$ \\
\hline & -PCA2 (DI-) & 24.320 & 4.466 & $0.033(9.4 \times)$ \\
\hline & $-\mathrm{dpop}_{t-1}(\mathrm{DDD})$ & 24.480 & 4.626 & $0.031(10.0 \times)$ \\
\hline \multirow[t]{6}{*}{ RJUV } & -djuv (DD) & 37.616 & 0.00 & 0.288 \\
\hline & - dpop (DD) & 37.717 & 0.101 & $0.274(1.1 \times)$ \\
\hline & - dyoy (DD) & 37.774 & 0.158 & $0.266(1.1 \times)$ \\
\hline & PCA1 (DI+) & 40.075 & 2.459 & $0.084(3.4 \times)$ \\
\hline & $\mathrm{dpop}_{t-1}(\mathrm{DD})$ & 41.657 & 4.041 & $0.038(7.6 \times)$ \\
\hline & $\mathrm{PCA} 2$ (DI+) & 42.107 & 4.491 & $0.031(9.3 \times)$ \\
\hline RYOY & - dyoy (DD) & 38.209 & 0.000 & 0.751 \\
\hline
\end{tabular}

Notes: $\mathrm{AIC}_{\mathrm{C}}$ represents the information lost in the data (i.e., entropy) via use of the explanatory model, and $\Delta \mathrm{AIC}_{\mathrm{C}}$ represents the information lost by use of a candidate model instead of the best-fitting model (i.e., model with lowest $\mathrm{AIC}_{\mathrm{C}}$ ).

$\dagger$ Importance weights $\left(w_{i}\right)$ represent the posterior probability $(0-1.0)$ that a candidate model is true given the data (likelihood best model true vs. model $Y$ ). Values in parentheses after $w_{i}$ values represent the probability that the best-fitting model is true, given the data, in comparison to the model being examined. For example, for BCA RPOP, the best-fitting model (DD) is 6.3 times more likely to be true given the data than the CDD model.

\section{Coweeta Creek.-}

1. Density and population stability.-Population densities and abundances in CC were quite stable (density $\mathrm{CV}=0.41$; population $\mathrm{CV}=0.39$ ). None of the total population estimates for $\mathrm{CC}$ violated the assumptions of the three-pass depletion method, and asymmetric $95 \%$ confidence intervals for density estimates varied from 0.3 to $1.4 \mathrm{sculpin} / \mathrm{m}^{2}$. As with $\mathrm{BCB}$, this range was strongly affected by a single annual confidence interval that ranged from 1.2 to $2.6 \mathrm{sculpin} / \mathrm{m}^{2}$. The drought did not affect population structure in CC, because there were no significant differences in the percentage of the population composed of either adults $(\mathrm{ND}=0.72, \mathrm{DR}=0.69 ; P=0.86)$ or juveniles (ND $=0.23, \mathrm{DR}=0.27 ; P=0.50)$ between drought and non-drought years. Nonetheless, population densities were significantly lower during the drought in CC (ND $=0.38$ sculpin $/ \mathrm{m}^{2}$, DR $=0.24$ sculpin $\left./ \mathrm{m}^{2} ; P=0.06\right)$. This result appeared to be due to a significant difference in adult density $\left(\mathrm{ND}=0.26 \mathrm{sculpin} / \mathrm{m}^{2}, \mathrm{DR}=0.18\right.$ sculpin $\left./ \mathrm{m}^{2} ; P=0.08\right)$, because we failed to detect significant differences in either juvenile (ND $=0.10$ scul- $\left.\mathrm{pin} / \mathrm{m}^{2}, \mathrm{DR}=0.06 \mathrm{sculpin} / \mathrm{m}^{2} ; P=0.30\right)$ or YOY (ND $=0.03$ sculpin $/ \mathrm{m}^{2}, \mathrm{DR}=0.03$ sculpin $/ \mathrm{m}^{2} ; P=0.25$ ) densities in drought and non-drought comparisons.

2. Sculpin per capita rate of change.-The dynamics of sculpin in CC were more complex than those of populations in BCA or BCB. Per capita rate of increase analysis for both population and juvenile life-history classes each yielded six interpretable models. Variation in $r$ for the population was fit almost equally well by models of positive DI, DD (dpop), and RL (YOY density two falls previously) (Tables 5 and 6), although the CI for DD (from 0.00011 to -0.64546 ) barely overlapped zero. There were several other interpretable models for population data, although their confidence intervals all included zero and only a second RL model $\left(\operatorname{djuv}_{t-1}\right)$ explained sufficient information to warrant interpretation (Tables 5 and 6). Patterns in $r$ for juveniles indicated that multiple DD models (i.e., djuv, dpop, and dyoy) were the most plausible explanatory models (Tables 5 and 6), and also the only interpretable models whose parameter estimates did not include zero. Data for YOY showed that DD was the only plausible model 
TABLE 6. Model-averaged parameter estimates, 95\% confidence intervals, and model-averaged Akaike importance weights for parameters in interpretable models.

\begin{tabular}{|c|c|c|c|c|}
\hline $\begin{array}{l}\text { Site and } \\
\text { response } \\
\text { variable }\end{array}$ & $\begin{array}{c}\text { Regression } \\
\text { parameter }(b) \\
\text { or intercept }\end{array}$ & Estimate & $95 \% \mathrm{CI}$ & $w_{i}$ \\
\hline \multicolumn{5}{|l|}{$\overline{\mathrm{BCA}}$} \\
\hline \multirow[t]{3}{*}{ RPOP } & intercept & -0.047 & 0.185 to $-0.090 \dagger$ & \\
\hline & - dpop & -0.309 & -0.017 to $-0.449 \dagger$ & 0.971 \\
\hline & $-\mathrm{dpop}_{t-1}$ & -0.127 & 0.018 to $-0.272 \dagger$ & 0.272 \\
\hline \multirow[t]{5}{*}{ RJUV } & intercept & 0.099 & 1.096 to 0.899 & \\
\hline & - djuv & -1.062 & 1.980 to $-0.144 \dagger$ & 0.577 \\
\hline & PCA1 & 0.738 & 1.866 to $-0.390 \dagger$ & 0.130 \\
\hline & - dpop & -0.672 & 0.414 to $-1.759 \dagger$ & 0.118 \\
\hline & - dyoy $_{t-1}$ & -0.431 & 0.716 to $-1.578 \dagger$ & 0.067 \\
\hline \multirow[t]{4}{*}{ RYOY } & intercept & 0.000 & 1.102 to 1.101 & \\
\hline & -dyoy & -1.759 & 3.029 to $-0.489 \dagger$ & 0.662 \\
\hline & $\mathrm{PCA} 2$ & 1.343 & 2.593 to 0.094 & 0.189 \\
\hline & $-\mathrm{PCA} 1$ & -1.069 & -0.092 to -2.046 & 0.181 \\
\hline \multicolumn{5}{|l|}{$\mathrm{BCB}$} \\
\hline \multirow[t]{2}{*}{ RPOP } & intercept & 0.024 & 0.189 to $-0.141 \dagger$ & \\
\hline & - dpop & -0.406 & -0.242 to -0.570 & 0.990 \\
\hline \multirow[t]{2}{*}{ RJUV } & intercept & 0.135 & 0.658 to $-0.388 \dagger$ & \\
\hline & - djuv & -1.171 & -0.652 to -1.690 & 0.982 \\
\hline \multirow[t]{2}{*}{ RYOY } & intercept & -0.034 & 0.575 to $-0.642 \dagger$ & \\
\hline & -PCA1 & -1.254 & -0.627 to -1.881 & 0.962 \\
\hline \multicolumn{5}{|l|}{$\mathrm{CC}$} \\
\hline \multirow[t]{7}{*}{ RPOP } & intercept & 0.131 & 0.500 to $-0.238 \dagger$ & \\
\hline & PCA1 & 0.345 & 0.655 to 0.034 & 0.323 \\
\hline & dyoy $_{t-2}$ & 0.590 & 1.139 to 0.041 & 0.278 \\
\hline & - dpop & -0.328 & $0.000 \ddagger$ to $-0.655 \dagger$ & 0.225 \\
\hline & $\operatorname{djuv}_{t-1}$ & 0.666 & 1.522 to $-0.190 \dagger$ & 0.111 \\
\hline & -PCA2 & -0.100 & 0.481 to $0.285 \dagger$ & 0.047 \\
\hline & - dpop $_{t-1}$ & 0.002 & 0.540 to $-0.544 \dagger$ & 0.036 \\
\hline \multirow[t]{7}{*}{ RJUV } & intercept & 0.046 & 0.736 to $-0.643 \dagger$ & \\
\hline & - djuv $^{\top}$ & -0.758 & 1.417 to $-0.098 \dagger$ & 0.288 \\
\hline & - dpop & -0.808 & -0.090 to -1.525 & 0.288 \\
\hline & dyoy $_{t-1}$ & -0.750 & -0.084 to -1.416 & 0.266 \\
\hline & PCA1 & 0.597 & 1.385 to $-0.192 \dagger$ & 0.089 \\
\hline & dpop $_{t-1}$ & 0.438 & 1.574 to $-0.697 \dagger$ & 0.052 \\
\hline & PCA2 & 0.256 & 1.121 to $-0.608 \dagger$ & 0.035 \\
\hline \multirow[t]{2}{*}{ RYOY } & intercept & 0.065 & 0.804 to $-0.675 \dagger$ & \\
\hline & - dyoy & -0.923 & -0.219 to -1.627 & 0.755 \\
\hline
\end{tabular}

$\dagger$ Confidence interval for the parameter includes zero.

$\$$ True value is 0.00011 .

capable of explaining variation in $r$ (Tables 5 and 6). Results of Dennis and Taper tests indicated that DD was present in all three life-history classes (population, $b=0.882, P<0.101$; juveniles, $b=-1.357, P<$ 0.02; YOY, $b=1.341, P<0.01)$.

The partitioned data set for YOY provided additional evidence of environmentally influenced density-dependent interactions among sculpin in $\mathrm{CC}$, because the density of juveniles in spring had a strong negative effect on autumn densities of YOY (density dependence, $r=0.56$, Fig. 4) in years with low flows.

\section{Removal experiment}

Population estimates for both control and removal sites demonstrated that sculpin abundance and population structure were relatively similar in all sites (adult abundance $=82-127$ sculpins, Table 7). Most importantly, the percentage of juveniles in the population in the pre-removal period only ranged from $25 \%$ to $35 \%$ in the four sites (Table 7). Analyses of habitat availability and use data in the four sites produced three significant components, the first of which represented a gradient of high-velocity microhabitats with erosional substrata vs. low-velocity sites dominated by depositional substrata (Fig. 5). Because this is the main habitat gradient in the stream (Grossman and Ratajczak 1998), we did not conduct habitat use analyses on the two remaining components.

The removal reduced the number of adults in the two sites by $73 \%$ (Shope Fork) and $75 \%$ (Ball Creek), respectively (Table 7), and there were no apparent microhabitat shifts (pre- and post-removal comparisons all nonsignificant) by juveniles in control sites (Fig. 5). By contrast, when adults were removed, juveniles shifted into microhabitats formerly occupied by adults in both sites (Fig. 5). 


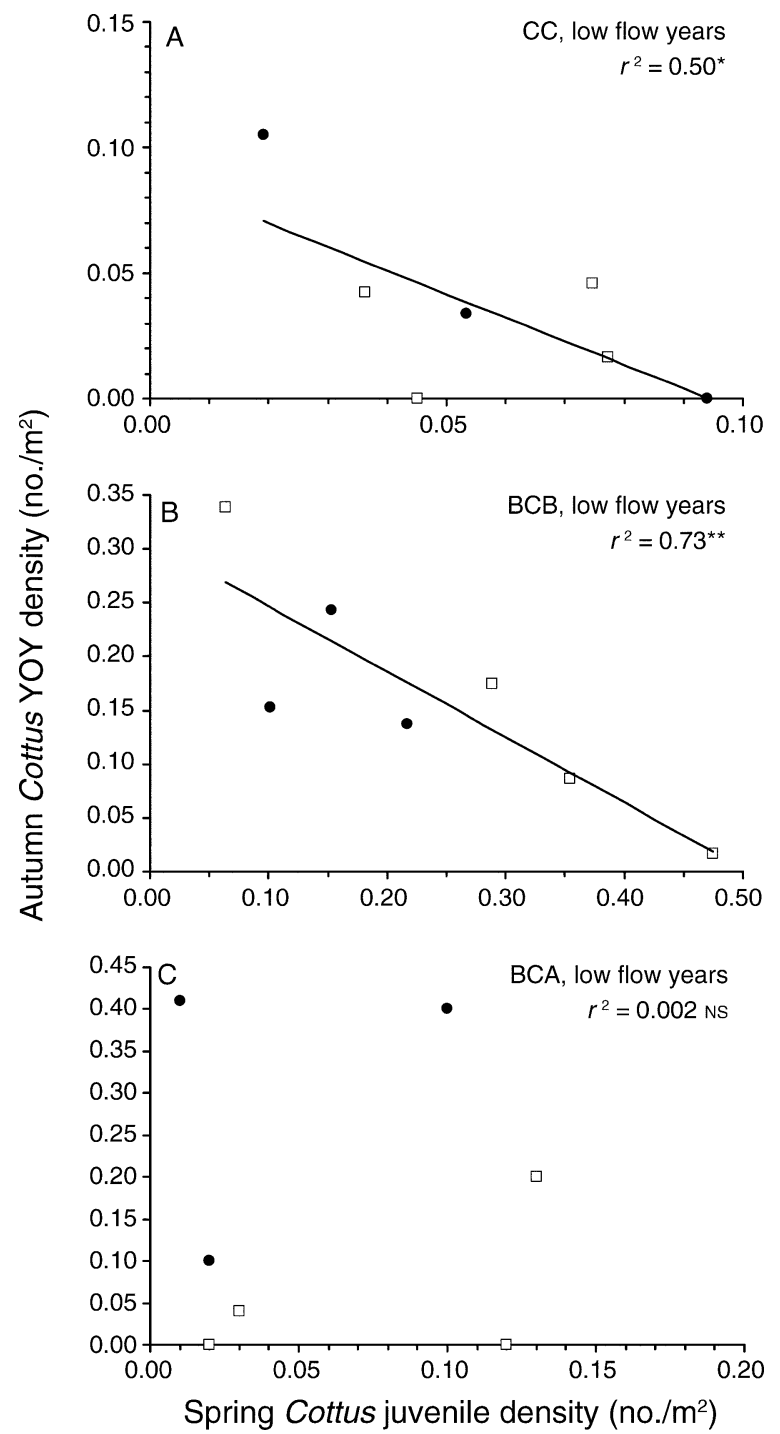

FIG. 4. Correlation (i.e., density-dependent relationship) between YOY density and juvenile density in (A) CC, (B) $\mathrm{BCB}$, and (C) BCA during low flow years (i.e., those with $<10$ high flow events). Solid circles represent data for the drought years of $1985-1988(N=4)$.

$* P<0.05 ; * * P<0.01$
Among-site comparisons
Population.-Comparisons among sites indicated that population densities of sculpin in BCA were the most stable $(\mathrm{CV}=0.23)$, whereas population densities in $\mathrm{CC}$ were the most variable $(\mathrm{CV}=0.41)$. These data also suggest that habitat affected population stability, because the rankings of these two variables were in agreement among sites (i.e., BCA, most stable habitat; $\mathrm{BCB}$, intermediate habitat stability; CC, lowest habitat stability). There also were differences in population densities among sites, and both pooled and drought data sets indicated that mean $( \pm \mathrm{SD})$ population densities were significantly higher in BCB $(0.51 \pm 0.18$ sculpin/ $\left.\mathrm{m}^{2}\right)$ than in $\mathrm{CC}\left(0.35 \pm 0.14 \mathrm{sculpin} / \mathrm{m}^{2}\right)$ (KruskalWallis test, $P=0.02$ ), (BCB vs. BCA $[0.35 \pm 0.08$ sculpin $\left./ \mathrm{m}^{2}\right]$, NS). In addition, the drought affected population density differently in the three sites, and only $\mathrm{CC}$ exhibited a significant drought effect (i.e., lower population densities). Population dynamics of sculpin in the three sites were asynchronous because multiple pairwise correlations of population $r$ failed to produce any significant correlation among sites during the 12yr study period. Identical results were obtained with density data. Finally, changes in length and mass data for the various life history classes indicated that BCA was probably the most suitable habitat during nondrought periods (see Adults and Juveniles, below; significantly greater length and mass measurements for both adults and juveniles), whereas BCB appeared to be the most favorable site for juveniles during the drought (significantly greater length and mass measurements).

1. Adults.-Variation in adult segments of sculpin populations was similar to that observed among populations. Densities in BCA were the most stable (CV $=0.28)$, whereas densities in $\mathrm{BCB}$ were somewhat more variable $(\mathrm{CV}=0.43)$. Finally, values for $\mathrm{CC}$ were similar to those for $\mathrm{BCB}$ (adult density $\mathrm{CV}=0.36$ ). Adult densities were higher in $\mathrm{BCB}(X \pm \mathrm{SD}=0.29$ $\left.\pm 0.12 \mathrm{sculpin} / \mathrm{m}^{2}\right)$ than in $\mathrm{CC}(0.23 \pm 0.08 \mathrm{sculpin} /$ $\left.\mathrm{m}^{2}\right)$ for both pooled and drought data sets $(P<0.05)$. Multiple pairwise correlation analyses on adult $r$ or density values yielded only a single significant correlation (adult density during drought periods, BCB vs.

TABLE 7. Population estimates (mean with SE in parentheses) and percentage of juveniles in the population for sculpin from control and removal sites.

\begin{tabular}{|c|c|c|c|c|c|c|c|c|}
\hline \multirow[b]{2}{*}{$\begin{array}{l}\text { Site and } \\
\text { treatment }\end{array}$} & \multicolumn{4}{|c|}{ Shope Fork } & \multicolumn{4}{|c|}{ Ball Creek } \\
\hline & Juveniles & $\begin{array}{l}\text { Small } \\
\text { adults }\end{array}$ & $\begin{array}{l}\text { Large } \\
\text { adults }\end{array}$ & $\begin{array}{c}\text { Juveniles } \\
(\%)\end{array}$ & Juveniles & $\begin{array}{l}\text { Small } \\
\text { adults }\end{array}$ & $\begin{array}{l}\text { Large } \\
\text { adults }\end{array}$ & $\begin{array}{c}\text { Juveniles } \\
(\%)\end{array}$ \\
\hline \multicolumn{9}{|l|}{ Control } \\
\hline Pre-removal & $33(2)$ & $72(8)$ & $27(3)$ & 25 & $44(5)$ & $99(9)$ & $28(1)$ & 26 \\
\hline Post-removal & $30(3)$ & $60(4)$ & $27(2)$ & 26 & 37 (3) & $81(9)$ & $23(2)$ & 26 \\
\hline \multicolumn{9}{|l|}{ Removal } \\
\hline Pre-removal & $44(3)$ & $52(5)$ & $30(2)$ & 35 & $42(4)$ & $61(6)$ & $40(4)$ & 29 \\
\hline Post-removal & $37(3)$ & $14(1)$ & $8(1)$ & 63 & $39(3)$ & $16(2)$ & $9(2)$ & 61 \\
\hline
\end{tabular}



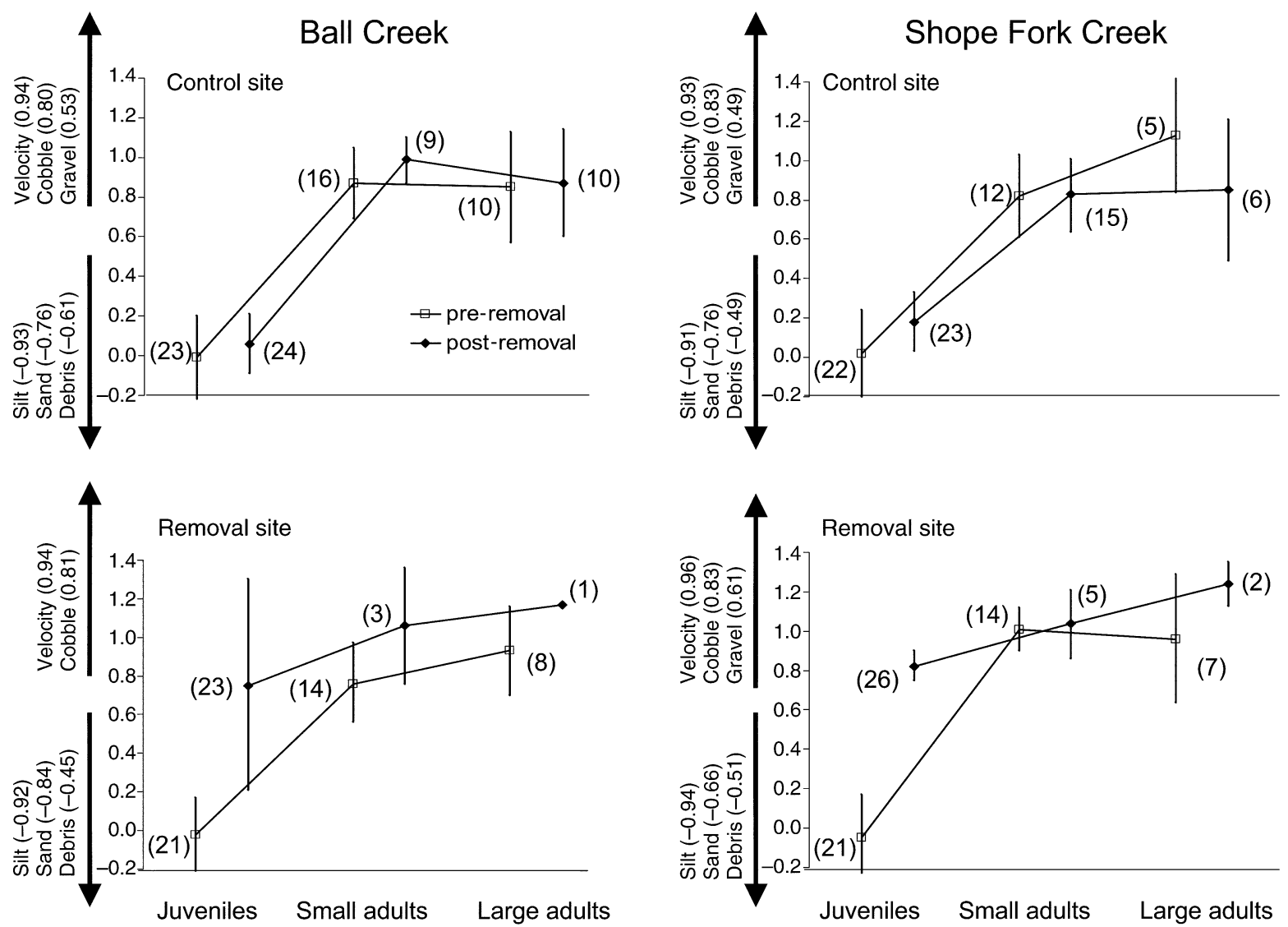

FIG. 5. Effects of adult sculpin removal on microhabitat use by juveniles. Principal component scores (PC1, mean and 95\% CI) for juvenile and small and large adults inhabiting control (C) and removal (R) sites are presented. We present variable loadings for PC1 on the $y$-axis of each graph, and sample sizes in parentheses adjacent to the data points.

BCA, $r=0.97, P=0.02$ ). During the non-drought period, adults in BCA were significantly longer (61 $\mathrm{mm})$ than in either $\mathrm{CC}(57 \mathrm{~mm})$ or $\mathrm{BCB}(54 \mathrm{~mm})$, whereas adults in $\mathrm{CC}$ also had significantly greater mean length than adults in BCB $(P \ll 0.01)$. During the non-drought period, adults were significantly heavier in BCA $(5.3 \mathrm{~g})$ and $\mathrm{CC}(4.5 \mathrm{~g})$ than in BCB (3.9 g) $(P \ll 0.01)$.

2. Juveniles.-The dynamics of juveniles were more similar among sites than any other life-history class. We observed significant correlations among all three sites for both pooled (BCA vs. BCB, $r=0.39, P=$ 0.03 ; BCA vs. CC, $r=0.74, P \ll 0.01$; BCB vs. CC, $r=0.25, P=0.10$ ) and non-drought (BCA vs. BCB, $r=0.51, P=0.05$; BCA vs. CC, $r=0.90, P \ll 0.01$; $\mathrm{BCB}$ vs. CC, $r=0.66, P=0.01$ ) data sets. During the drought, this relationship also was present between $\mathrm{BCA}$ and $\mathrm{CC}\left(r^{2}=0.95, P=0.03\right)$. Per capita rates of change for juveniles in BCA and $\mathrm{CC}$ also were significantly correlated in the pooled data set $(r=0.89$, $P \ll 0.01)$. These results suggest that environmental or biological factors common to all three sites affected $r$ and density of the juvenile life-history class.
We observed several differences in the demographic characteristics of juveniles among sites. During the drought juveniles were significantly longer in BCB (33 $\mathrm{mm})$ than in either $\mathrm{CC}(30 \mathrm{~mm})$ or BCA $(26 \mathrm{~mm})(P$ $\ll 0.01$ ), whereas juveniles in CC also had significantly greater mean lengths than juveniles in BCA $(P \ll 0.01)$. In non-drought years, juveniles in BCA had significantly greater mean lengths $(32 \mathrm{~mm})$ than juveniles in CC $(30 \mathrm{~mm})(P \ll 0.01)$. In addition, juveniles were significantly heavier in $\mathrm{BCB}(0.83 \mathrm{~g})$ during the drought than in either $\mathrm{CC}(0.67 \mathrm{~g})$ or BCA $(0.43 \mathrm{~g})$, whereas juveniles in $\mathrm{CC}$ also had significantly greater mean mass than juveniles in BCA $(P \ll 0.01)$. During the non-drought period, juveniles in BCA had significantly greater mean mass than juveniles in $\mathrm{CC}(P=$ $0.04)$.

3. Young-of-the-year.-Dynamics of YOY differed among the three sites. Pooled data sets indicated that YOY density was significantly higher in $\mathrm{BCB}(0.12 \pm$ $\left.0.10 \mathrm{sculpin} / \mathrm{m}^{2}\right)$ than in CC $\left(0.02 \pm 0.03 \mathrm{sculpin} / \mathrm{m}^{2}\right.$, $P=0.03)$. In addition, YOY densities were not significantly correlated among sites with one exception (non-drought data for $\mathrm{BCA}$ and $\mathrm{BCB}, r=0.70, P=$ $0.01)$. 


\section{DiscUSSION}

Our 12-yr descriptive study, combined with data from related studies (Petty 1998, Petty and Grossman 2004) and a field removal experiment, demonstrated that multiple processes were capable of explaining per capita rate of increase data for sculpin in the Coweeta Creek drainage. Nonetheless, simple density dependence had the greatest explanatory power, although the importance of this process varied somewhat between methods and among sites. Using Dennis and Taper's (1994) method, simple density dependence was present in all life-history classes in all sites. In addition, when we used a strong-inference approach with AIC, simple density dependence was the most plausible model, or dominated the set of plausible models, for seven of nine cases. The AIC analysis also suggested that density-dependent relationships were stronger in BCA and BCB than in CC. Sculpin populations in both BCA and $\mathrm{BCB}$ had both higher densities and lower variability and the sites displayed greater physical stability than CC. By contrast, DI was the most plausible explanatory model only for YOY in $\mathrm{BCB}$, although it also was one of three (DD, RL) equally plausible models for the population in CC. Similar to DI, recruitment limitation only was a plausible explanation for variation in population data in CC, where it had equal plausibility with DD and DI.

Results from the removal experiment provide direct, albeit short-term, evidence that DD may have a strong impact on sculpin populations. Previous studies in our laboratory also have shown that adult sculpin display many characteristics that suggest they are competitively superior to juveniles (see Introduction). In addition, the high stability of sculpin populations in the three sites, despite one of the worst droughts in the last century (Grossman et al. 1998), suggests that densitydependent compensatory relationships may be a general feature of these populations.

One puzzling result of our analyses, given the findings of the removal experiment, is that the most plausible DD model for most life-history classes was the density of the same life-history class (i.e., most plausible model for rjuv was djuv) rather than population density. However, given the high numerical stability of the population and adults in this system, it is probable that more variance in $r$ was explained by variations in the density of individuals within the competitively inferior life-history class than by the observed low-level variation in the densities of superior competitors. These results, coupled with the fact that juvenile density generally had little impact on population size, suggest that many juveniles experience high mortality in this system. Although we cannot discount juvenile emigration as a process affecting high stability of sculpin populations, it is inconsistent with our previous results for juvenile movement (Petty and Grossman 2004).
Despite the fact that DD was the most plausible model for most sculpin life-history classes, negative DI was the most plausible model explaining $r$ for YOY (negative DI, PCA1) in BCB, and one of three equally plausible models (positive DI, PCA1) for the population in CC. The hypothesized mode of operation for negative DI is via mortality produced by high flow events, a phenomenon observed in many stream fishes (Grossman et al. 1982) including other Cottus (Erman et al. 1988). By contrast, positive DI is produced by favorable environmental conditions that increase survivorship of individuals and may represent an indirect form of habitat limitation (i.e., higher flows probably increase habitat availability) that ultimately may result in DD. In addition, partitioned data sets elucidated a clear relationship between flows and YOY density in $\mathrm{BCA}$, and a DI $\times \mathrm{DD}$ interaction between juveniles and YOY in BCB and $\mathrm{CC}$ in low flow years. Consequently, although DI was not a plausible model for most data sets, it appeared to influence both YOY density and YOY $\times$ juvenile interactions in all sites.

Recruitment limitation was one of three equally plausible models explaining variation in $r$ for the population in $\mathrm{CC}$, and presumably represented a case where variations in YOY survivorship were translated upward to the juvenile life-history class and ultimately the population. Variations in YOY survivorship probably were influenced by several factors including: (1) frequencies of high flow events in both drought and non-drought years, (2) mean water levels, especially in non-drought years, (3) density-dependent competitive interactions with juveniles in years with low flows, and (4) densitydependent competitive interactions with YOY in the previous year. The last response was unexpected, although it was detected in YOY $r$ for both BCA and CC. Because $\mathrm{YOY}_{t}$ and $\mathrm{YOY}_{t-1}$ can only interact directly as $\mathrm{YOY}_{t}$ and juveniles $\left(\mathrm{YOY}_{t-1}\right)$, it is curious that a density-dependent interaction was not noted between these life-history classes at time $t$. It is possible that this interaction involved a reduction in resource availability (either food or space) by $\mathrm{YOY}_{t-1}$, which then resulted in decreased survivorship of $\mathrm{YOY}_{t}$, similar to biennial cycles of mast production observed in some trees (Crawley and Long 1995). Interage class competitive interactions have been observed in several other fish species (Townsend et al. 1990).

Although our sites are located within $2 \mathrm{~km}$ of each other, there is evidence that they are functioning as separate demographic units. First, BCA, BCB, and CC displayed slightly different dynamics, even though DD generally was the most plausible model explaining demographic variation in the three sites. Second, sculpin generally move only short distances (i.e., $<2 \mathrm{~m}$ ) even over multimonth periods (Petty and Grossman 2004). Third, there were few correlations among sites for either $r$ or density for: (1) population, (2) adult, and (3) YOY life-history classes. The juvenile life-history class did show significant among-site correlations in 
both $r$ and density, which suggests that the dynamics of this life-history class were influenced by common factors regardless of site. Fourth, drought-induced changes in the mean length and mass of sculpin were present in all three sites; however declines in densities were only observed in CC (population and adults) and BCB (adults). In addition, different sites appeared to represent more favorable habitat (i.e., greater fish length or mass) for different life-history classes during the two periods. For example, BCA appeared to be better habitat for adults during the non-drought period, whereas BCB appeared to be the best habitat for juveniles during the drought. These findings suggest that there may be small-scale demographic differentiation in sculpin inhabiting the Coweeta drainage.

In addition to the spatial variation present in this system, there also was significant temporal variation in the demographic processes examined during our study. For example, the demographic consequences of several physical factors (i.e., flow levels) and densitydependent interactions varied temporally in all three sites (Figs. 4 and 5). These findings suggest that the processes controlling $r$, and ultimately, sculpin abundance, in the Coweeta drainage may be significantly affected by both the temporal and spatial location of the population being studied. Such context dependency has been noted by other investigators studying animal population dynamics (Booth 1995), and should serve as a caveat for studies conducted in one location or over short time spans.

\section{Regulation of stream fish populations}

Although stream fish populations have been extensively studied by resource managers, there have been relatively few attempts to delineate the processes determining population size in these species, especially for non-salmonids. The most convincing evidence of density-dependent population regulation in stream fishes comes from studies of salmonid fishes (Grant and Kramer 1990, Elliott 1994). When density-dependent processes have been identified in these species, they typically take the form of strong intraspecific competition for feeding sites among: (1) YOY, (2) juveniles $(1+$ age class), or (3) both age classes, which leads to production of a given number of mature individuals, and hence determines adult population size (Grant and Kramer 1990, Elliott 1994). Typically there is less evidence of density-dependent interactions between juveniles and adults (but see Nakano and Nagoshi 1985, Latterell et al. 1998, Jenkins et al. 2004), or among adults themselves. Consequently, adult population size is dependent upon both the amount of suitable habitat available for YOY (or juvenile) territories in a given year combined with the total number of YOY produced in that year (Grant and Kramer 1990, Elliott 1994). In these systems adult population size may vary substantially from year to year, even though strong densitydependent regulation is present in the population (Grant and Kramer 1990, Elliott 1994). This pattern differs somewhat from that exhibited by sculpin in the Coweeta drainage. Sculpin displayed high stability in both population and adult densities, a phenomenon likely produced by mortality or low-level emigration of juveniles. In addition, DD was the most parsimonious explanation for $r$ for most adult and all juvenile lifehistory classes. Given the differences in density-dependent interactions identified in both this and previous studies, it is clear that density-dependent interactions within stream fish populations may take a variety of forms.

The frequency of density-dependent population regulation in stream fishes is unknown at present, although recent studies have demonstrated the presence of density-dependent survivorship, growth, and abundance relationships in several common non-salmonid fishes (Schlosser 1998, Grenouillet et al. 2001, Matthews et al. 2001). Nonetheless, there is strong evidence that density-independent processes also have a major impact on fishes in these habitats (Grossman et al. 1982, 1998). Indeed, although our data document the dominance of density-dependent processes for sculpin in the Coweeta drainage, earlier work demonstrates that density-independent factors (flow variation) dominate assemblage-level characteristics in a nearby site in the same drainage (Grossman et al. 1998). In a review of the stability of stream fish populations, Grossman et al. (1990) found that most stream fishes exhibited low population stability with mean population abundance CVs ranging between 0.99 and 1.05 , depending on the data set. Although direct evidence frequently is lacking, it is hypothesized that negative DI affects stream fishes via mortality produced by aperiodic environmental disturbances (e.g., floods, droughts, harsh winters, etc.).

The mottled sculpin is a widely distributed species that frequently is the most abundant fish in North American streams (Grossman et al. 2002). Using AIC, we were able to use a strong inference approach to assess the relative plausibility of several processes (DD, DDD, CDD, DI, RL and mixed models) as explanatory mechanisms for variation in sculpin in the Coweeta drainage. Our results, including tests for DD using the Dennis and Taper (1994) method, suggest that simple density dependence is the most likely mechanism affecting the per capita rate of increase of sculpin populations in the Coweeta drainage. In addition, our removal experiment, coupled with results from prior studies, suggests that intraspecific competition for profitable microhabitats may have produced the observed DD relationships in population data. These findings add support to the growing body of evidence documenting the importance of density dependence to a variety of taxa, including mammals (Choquenot 1991, Dennis and Taper 1994), birds (Gauthier and Smith 1987), reptiles (Massot et al. 1992), amphibians (Wilbur 1977, Petranka 1989), fishes (Elliot 1994, Schmitt and Holbrook 
1999), and invertebrates (Cappuccino and Price 1995). Nevertheless, population regulation of sculpin in the Coweeta drainage was a complex phenomenon because we also observed minor density-independent effects, a DD $\times$ DI interaction for YOY, and small-scale spatial differences in population processes. These findings argue for a multitiered approach to the study of population variation, one that encompasses long-term monitoring, spatial variation, and experimental testing of potential mechanisms.

\section{ACKNOWLEDGMENTS}

We would like to acknowledge the many individuals who contributed to the success of this project: Mary Freeman, Maurice Crawford, Barbara Grossman, Patricia Petty, Bridgette Ratajczak, MaryCarol Rossiter, Pedro Rincon, Jeff Barrett, Deanna Stouder, Jennifer Hill, Doug Facey, Mark Farr, Jerry Freilich, Andrew Thompson, and the staff of Jittery Joes. In addition, long-term site access and logistical support were provided by James Vose, and the staff of the U.S.D.A. Forest Service Coweeta Hydrologic Laboratory. This research was funded via long-term support from the U.S.D.A. Forest Service McIntire-Stennis program (grants GEO-0035-MS, GEO-0042-MS, GEO-0047-MS and GEO-0086-MS) and the National Science Foundation (BSR-9011661, DEB-9632854, DEB-2018001). Additional support was provided by the Daniel B. Warnell School of Forest Resources. The manuscript was typed by Annelle Nelms, Sommer Garrison, and Tina Jones and benefited from the comments of J. Carroll, M. Farr, K. Fausch, C. Gibson, K. McDaniel, D. Promislow, P. Rincon, $\mathrm{M}$. Wagner, and an anonymous reviewer.

\section{Literature Cited}

Barrett, J. C. 1989. The effects of competition and resource availability on the behavior, microhabitat use and diet of the mottled sculpin (Cottus bairdi). Dissertation. University of Georgia, Athens, Georgia, USA.

Booth, D. J. 1995. Juvenile groups in a coral-reef damselfish: density-dependent effects on individual fitness and population demography. Ecology 76:91-106.

Box, G. E. P., and G. M. Jenkins. 1976. Time series analysis: forecasting and control. Holden-Day Press, San Francisco, California, USA.

Buckland, S. T., K. P. Burnham, and N. H. Augustin. 1997. Model selection: an integral part of inference. Biometrics 53:603-618.

Burnham, K. P., and D. R. Anderson. 2002. Model selection and multimodel inference: a practical information-theoretical approach. Second edition. Springer-Verlag, New York, New York, USA.

Cappuccino, N., and P. W. Price. 1995. Population dynamics: new approaches and synthesis. Academic Press, San Diego, California, USA.

Choquenot, D. H. 1991. Density-dependent growth, body condition and demography in feral donkeys: testing the food hypothesis. Ecology 72:805-813.

Crawley, M. J., and C. R. Long. 1995. Alternate bearing, predator satiation and seedling recruitment in Quercus robur L. Journal of Ecology 83:683-696.

Danilowicz, B. S. 1997. A potential mechanism for episodic recruitment of a coral reef fish. Ecology 78:1415-1423.

DeHaven, J. E., D. J. Stouder, R. Ratajczak, T. J. Welch, and G. D. Grossman. 1992. Reproductive biology of mottled sculpin (Cottus bairdi), rosyside dace (Clinostomus funduloides) and longnose dace (Rhinichthys cataractae) in a southern Appalachian stream. Ecology of Freshwater Fish 1:104-111.
Dennis, B., and M. R. Otten. 2000. Joint effects of density dependence and rainfall on abundance of San Joaquin kit fox. Journal of Wildlife Management 64:388-400.

Dennis, B., and M. Taper. 1994. Density dependence in time series observations of natural populations: estimation and testing. Ecological Monographs 64:205-224.

Elliott, J. M. 1994. Quantitative ecology and the brown trout. Oxford University Press, London, UK.

Erman, D. C., E. D. Andrews, and M. Yoder-Williams. 1988. Effects of winter floods on fishes in the Sierra Nevada. Canadian Journal of Fisheries and Aquatic Sciences 45: 2195-2200.

Freeman, M. C., M. Crawford, J. Barrett, D. E. Facey, M. Flood, J. Hill, D. J. Stouder, and G. D. Grossman. 1988. Stability of fish assemblages in a Southern Appalachian stream. Canadian Journal of Fisheries and Aquatic Sciences 45:1949-1958.

Fretwell, S. D. 1972. Populations in seasonal environments. Princeton University Press, Princeton, New Jersey, USA.

Gauthier, G., and J. N. M. Smith. 1987. Territorial behavior, nest-site availability and breeding density in buffleheads. Journal of Animal Ecology 56:171-184.

Grant, J. W. A., and D. L. Kramer. 1990. Territory size as a predictor of the upper limit to population density of juvenile salmonids in streams. Canadian Journal of Fisheries and Aquatic Sciences 47:1724-1737.

Grenouillet, G., B. Hugueny, G. A. Carrel, J. M. Olivier, and D. Pont. 2001. Large-scale synchrony and inter-annual variability in roach recruitment in the Rhone River: the relative role of climatic factors and density-dependent processes. Freshwater Biology 46:11-26.

Grossman, G. D., J. F. Dowd, and M. C. Crawford. 1990. Assemblage stability in stream fishes: a review. Environmental Management 14:661-671.

Grossman, G. D., and M. C. Freeman. 1987. Microhabitat use in a stream fish assemblage. Journal of Zoology (London) 212:151-176.

Grossman, G. D., J. Hill, and J. T. Petty. 1995a. Observations on habitat structure, population regulation, and habitat use with respect to evolutionarily significant units: a landscape approach for lotic systems. Pages 381-391 in J. L. Nielsen, editor. Evolution and the aquatic ecosystem: American Fisheries Society Symposium. 17. American Fisheries Society, Bethesda, Maryland, USA.

Grossman, G. D., K. McDaniel, and R. E. Ratajczak, Jr. 2002. Demographic characteristics of female mottled sculpin, Cottus bairdi, in the Coweeta Creek drainage, North Carolina. Environmental Biology of Fishes 63:299-308.

Grossman, G. D., P. B. Moyle, and J. R. Whitaker, Jr. 1982. Stochasticity in structural and functional characteristics of an Indiana stream fish assemblage: a test of community theory. American Naturalist 120:423-454.

Grossman, G. D., and R. E. Ratajczak, Jr. 1998. Long-term patterns of microhabitat use by fish in a southern Appalachian stream from 1983 to 1992: effects of hydrologic period, season and fish length. Ecology of Freshwater Fish 7:108-131.

Grossman, G. D., R. E. Ratajczak, Jr., and M. K. Crawford. 1995b. Do rock bass (Ambloplites rupestris) induce microhabitat shifts in mottled sculpin (Cottus bairdi)? Copeia 1995:343-353.

Grossman, G. D., R. E. Ratajczak, Jr., M. K. Crawford, and M. C. Freeman. 1998. Effects of environmental variation and interspecific interactions on assemblage structure and microhabitat use by stream fishes. Ecological Monographs 68:395-420.

Hixon, M. A., S. W. Pacala, and S. A. Sandin. 2002. Population regulation: historical context and contemporary challenges of open vs. closed systems. Ecology 83:14901508 . 
Hunter, M., and P. W. Price. 1998. Cycles in insect populations: delayed density-dependence or exogenous driving variables? Ecological Entomology 23:216-222.

Jenkins, T. M., S. Diehl, K. Kratz, and S. D. Cooper. 2004. Effects of population density on individual growth of brown trout in streams. Ecology 80:941-956.

Lake, P. S. 2000. Disturbance, patchiness, and diversity in streams. Journal of the North American Benthological Society 19:573-592.

Latterell, J. J., K. D. Fausch, C. Gowan, and S. C. Riley. 1998. Relationship of trout recruitment to snowmelt runoff flows and adult trout abundance in six Colorado mountain streams. Rivers 6:240-250.

Massot, M., J. Clobert, T. Pilorge, J. Lecomte, and R. Barbault. 1992. Density dependence in the common lizard: demographic consequences of a density manipulation. Ecology 73:1742-1756.

Matthews, W. J., K. B. Gido, and E. Marsh-Matthews. 2001. Density-dependent overwinter survival and growth of red shiners from a southwestern river. Transactions of the American Fisheries Society 130:478-488.

McIntosh, R. 1985. The background of ecology. Cambridge University Press, Cambridge, UK.

Murdoch, W. W. 1994. Population regulation in theory and practice. Ecology 75:271-287.

Nakano, S., and M. Nagoshi. 1985. Density regulation and growth of a redspot masu-trout, Oncorhynchus rhodurus, in a mountain stream. Physiological Ecology (Japan) 22: $1-16$.

Neter, J., W. Wasserman, M. H. Kutner, and C. J. Nachtsheim. 1996. Applied linear statistical models. McGraw-Hill, New York, New York, USA.

Peterson, J. T., R. F. Thurow, and J. W. Guzevich. 2004. An evaluation of multipass electrofishing for estimating the abundance of stream-dwelling salmonids. Transactions of the American Fisheries Society 133:462-475.

Petranka, J. W. 1989. Density-dependent growth and survival of larval Ambystoma: evidence from whole-pond manipulations. Ecology 70:1752-1767.

Petty, J. T. 1998. Mottled sculpin in a dynamic landscape: linking environmental heterogeneity, individual behaviors, and population dynamics in a southern Appalachian stream. Dissertation. University of Georgia, Athens, Georgia, USA.

Petty, J. T., and G. D. Grossman. 1996. Patch selection by mottled sculpin (Pisces: Cottidae) in a southern Appalachian stream. Freshwater Biology 35:261-276.
Petty, J. T., and G. D. Grossman. 2004. Restricted movement by mottled sculpin (Pisces: Cottidae) in a southern Appalachian stream. Freshwater Biology 49:631-645.

Platt, J. R. 1964. Strong inference. Science 146:347-353.

Poff, N. L., and J. D. Allan. 1995. Functional organization of stream fish assemblages in relation to hydrological variability. Ecology 76:606-627.

Pulliam, H. R. P., and B. Danielson. 1991. Sources, sinks and habitat selection: a landscape perspective on population dynamics. American Naturalist 137:S50-S66.

SAS Institute. 1985. SAS user's guide: statistics. Cary, North Carolina, USA.

Schlosser, I. J. 1998. Fish recruitment, dispersal and trophic interactions in a heterogeneous lotic environment. Oecologia 113:260-268.

Schmitt, R. J., and S. J. Holbrook. 1999. Mortality of juvenile damselfish: implications for assessing processes that determine abundance. Ecology 80:35-50.

Shenk, T. M., G. C. White, and K. P. Burnham. 1998. Sampling-variance effects on detecting density dependence from temporal trends in natural populations. Ecological Monographs 68:445-463.

Stouder, D. J. 1990. Dietary fluctuations in stream fishes and the effects of benthic species interactions. Dissertation. University of Georgia, Athens, Georgia. USA.

Stuart, A., and J. K. Ord. 1991. Kendall's advanced theory of statistics. Volume 2. Classical inference and relationship. Oxford University Press, New York, New York, USA.

Thompson, A. R., J. T. Petty, and G. D. Grossman. 2001. Multi-scale effects of resource patchiness on foraging behaviour and habitat use by longnose dace, Rhinichthys cataractae. Freshwater Biology 46:145-161.

Townsend, C. R., W. J. Sutherland, and M. Perrow. 1990. A modeling investigation of population cycles in the fish $R u$ tilus rutilus. Journal of Animal Ecology 59:469-485.

Turchin, P., and I. Hanski. 2001. Contrasting alternative hypotheses about rodent cycles by translating them into parameterized models. Ecology Letters 4:267-276.

White, G. C., D. R. Anderson, K. P. Burnham, and D. L. Otis. 1982. Capture-recapture and removal methods for sampling closed populations. Los Alamos National Laboratory Publication LA-8787-NERP.

Wilbur, H. M. 1977. Density-dependent aspects of growth and metamorphosis in Bufo americanus. Ecology 58:196200.

Zar, J. R. 1996. Biostatistical analysis. Third edition. Prentice-Hall, Englewood Cliffs, New Jersey, USA.

\section{APPENDIX}

A figure showing an example length frequency histogram for mottled sculpin in Coweeta Creek and a map of the Coweeta drainage depicting the spatial locations of the study sites (Ecological Archives M076-008-A1). 